\title{
LAS SEDES DE LOS SERVICIOS CENTRALES DEL INSTITUTO NACIONAL DE COLONIZACIÓN Y LA CUENCA DEL EBRO
}

\section{THE HEADQUARTERS OF THE CENTRAL SERVICES OF THE NA- TIONAL INSTITUTE OF COLONIZATION AND THE EBRO BASIN}

\author{
JOSÉ MARÍA ALAGÓN LASTE ${ }^{1}$ \\ Universidad de Zaragoza
}

Recibido: 14/06/2019 Aceptado: 04/12/2019

\section{RESUMEN}

El objetivo de nuestro estudio es el análisis de las diferentes etapas que han marcado la instalación de las oficinas del Instituto Nacional de Colonización, así como su organización interna, tanto de los Servicios Centrales, en Madrid, como en las diferentes sedes de la cuenca del Ebro, es decir, la de la Delegación Regional del Ebro, en Zaragoza; y la de la Delegación del INC en Lérida, dado que fueron las dos oficinas desde las que se realizaron los trabajos en este territorio y las únicas que se mantuvieron en la zona durante el funcionamiento del INC y el IRYDA, mientras que las demás, como la de Tortosa, tuvieron un uso más esporádico.

Palabras clave: arquitectura contemporánea, posguerra, colonización agraria, pueblos de colonización, Instituto Nacional de Colonización.

1 Doctor en Historia del Arte. Su tesis doctoral, titulada "Pueblos de Colonización en la cuenca del Ebro: urbanismo, arquitectura y arte", realizada en el Departamento de Historia del Arte de la Universidad de Zaragoza bajo la dirección de la doctora Mónica Vázquez Astorga, fue defendida en junio de 2017. 


\begin{abstract}
The goal of our study is the analysis of the different stages that marked the establishment of the offices of the National Institute of Colonization (INC in Spanish) as well as its internal organization, both of the Central Services in Madrid, as well as in the different regional offices along the Ebro basin: the Regional Delegation of the Ebro, in Zaragoza and the Delegation of the INC in Lleida. These two regional offices were in charge of the development of the INC plans and the only ones that remained in the area all the time the INC and the IRYDA were operational, whereas the other regional offices, such as Tortosa, had a more sporadic use.
\end{abstract}

Keywords: contemporary architecture, post-war period, agrarian colonization, colonization settlements, National Institute of Colonization. 
El Instituto Nacional de Colonización, organismo creado en 1939 para llevar a cabo la política de colonización agraria emprendida en la posguerra española, cuidó desde el primer momento su imagen institucional. Por este motivo, puso una especial atención en la elección de la situación de sus sedes, tanto la central, en Madrid, como las regionales y provinciales. En consecuencia, se dictaron normas para proceder a la designación del edificio más adecuado para este fin.

En un primer momento, tanto la sede Central como las denominadas Brigadas de Información se ubicaron en residencias accidentales -en el caso de la del Ebro, en la propia vivienda del jefe de la Brigada-, pero enseguida se fueron situando en otros emplazamientos más adecuados.

Así, la circular interna núm. 14 del INC, de 13 de febrero de 1941, reguló el establecimiento de las sedes de las Brigadas. En ella se refería su instalación provisional en la zona designada, donde, previo estudio de las circunstancias concretas, se debía manifestar si se estimaba que la residencia que había sido fijada como provisional para la Brigada reunía las condiciones adecuadas para instituirse con carácter definitivo, o si ésta debía de modificarse a otro emplazamiento distinto $^{2}$. También se contemplaba la posibilidad de acomodar provisionalmente las oficinas en algunos locales hasta que se construyeran los nuevos pueblos, entendiendo que si se disponía la Brigada de trabajo en uno de los núcleos de colonización estaría más próxima al centro de gravedad económico de la zona, lo que facilitaría su trabajo ${ }^{3}$.

Después, la circular interna núm. 13 del INC, de 16 de septiembre de 1941, estableció las normas relativas al régimen de residencias y alquiler de locales para las jefaturas de Brigada. En ella se señalaban las diferentes cuestiones a tener en cuenta en el establecimiento de los servicios del INC, haciendo especial hincapié en la importancia de la elección de los edificios:

2 AHPZ, Sección INC, Caja A/39895, Circular interna del Instituto Nacional de Colonización núm. 14: "Instalación de la Brigada", 13 de febrero de 1941.

3 A este respecto, es interesante mencionar que en algunos de los núcleos de colonización se instalaron pequeñas oficinas de explotación de forma temporal, ocupadas principalmente por personal técnico (como peritos agrícolas y mayorales). Hay que tener en cuenta que una vez que las tierras se estaban preparando para la llegada de los riegos y de los nuevos pobladores, el INC se vio en la necesidad de enviar personal a la zona. En el término municipal de Almudévar, por ejemplo, antes de construir el pueblo de San Jorge, núcleo en el que se instalarían las oficinas de Colonización para los tres pueblos de este término (Artasona del Llano, San Jorge y Valsalada), se instalaron unas oficinas provisionales en el Ayuntamiento de Almudévar (Huesca). Una vez que se terminó el pueblo, éstas se trasladaron a los locales de la Hermandad Sindical de esta localidad. «Sesión de aprobación del presupuesto de ordinario para 1956», Almudévar, 9 de octubre de 1955, en Archivo Municipal de Almudévar (AMA), Lib. 483: «Actas del pleno: 26 de julio de 1953-23 de septiembre de 1956», p. 74 (vuelta). 
"Es firme propósito de esta Dirección General que todas las oficinas de las Brigadas tengan la dignidad que corresponde a un Servicio del Estado y un sello peculiar que identifique y caracterice a las del Instituto Nacional de Colonización. Las residencias oficiales deben instalarse en edificios de primer orden, a ser posible de reciente construcción, y, desde luego, en vías principales y en el centro de actividad de la población donde radiquen otros edificios públicos, dependencias del Estado y edificios bancarios o de grandes empresas" 4 .

Igualmente, se mencionaba la importancia de que el piso que se alquilara para tal efecto cumpliera algunas condiciones necesarias, como que su emplazamiento permitiera la entrada de luz directa en todos los espacios destinados a despachos, que estuviera provisto de calefacción, que reuniera las debidas condiciones higiénicas, y que el portal y la escalera principal del edificio tuvieran "el aspecto que corresponde al carácter representativo de la oficina". Asimismo, las oficinas a instalar "en capitales de provincia, cabezas de Partido Judicial o pueblos mayores de 10.000 habitantes que tengan un carácter marcadamente urbano" debían ser decoradas tomando como norma el esquema que se acompañaba a esta circular ${ }^{5}$.

Respecto al mobiliario de las oficinas, esa circular establecía que había de ser sencillo y, a ser posible, de madera de roble americano. Se instalarían, aparte de las mesas y sillas, un armario biblioteca en el despacho del jefe; y ficheros, armarios metálicos y archivadores en el resto de los despachos ${ }^{6}$. Como motivos decorativos únicamente se dispondrían "los retratos del Generalísimo y José Antonio, así como los planos generales de España de Colonización, los propios de la zona y otros documentos gráficos, siempre en relación con el Servicio” (figura 1).

4 AHPZ, Sección INC, Caja A/39895, Circular interna del Instituto Nacional de Colonización núm. 13: "Residencias y alquiler de locales para las jefaturas de Brigada", 16 de septiembre de 1941. Asimismo, se estableció la fecha de $1^{\circ}$ de noviembre para que todas las unidades tuvieran firmados los contratos de alquiler de local para instalar su residencia oficial.

5 La conservación de estas oficinas, tal como estableció la circular número 112, así como las reparaciones a realizar, correspondían al arquitecto encargado de cada Delegación. En las Delegaciones que no hubiese arquitecto estas atribuciones corresponderían al aparejador, y, en su defecto, a un perito agrícola. AHPZ, Sección INC, Caja A/39896, Circular interna del Instituto Nacional de Colonización núm. 112: "Material de oficinas y conservación de locales", 3 de agosto de 1943.

6 La circular número 14 señalaba que, en caso de que próxima a la localidad donde se instalara la residencia existiera alguna oficina perteneciente a las suprimidas Delegaciones del Instituto de Reforma Agraria, se podrían utilizar sus muebles. AHPZ, Sección INC, Caja A/39895, Circular interna del Instituto Nacional de Colonización núm. 14: "Instalación de la Brigada", 13 de febrero de 1941. 


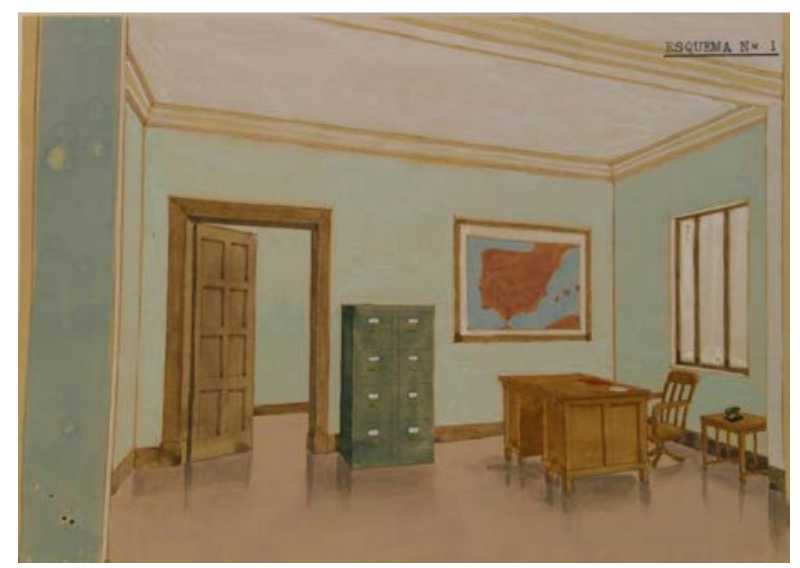

Fig. 1. Esquema de oficina para el INC, según la circular núm. 13, 1941 (Fuente: AHL, Lérida).

En esta circular se fijó también el uniforme para los conductores, ordenanzas y botones del Instituto, que podrían usar los de Falange Española Tradicionalista y de las Juntas de Ofensiva Nacional Sindicalista (FET y de las JONS) en caso de ser afiliados, o el modelo establecido por la Dirección General, que consistía en traje chaqueta-pantalón y una gorra (figura 2).

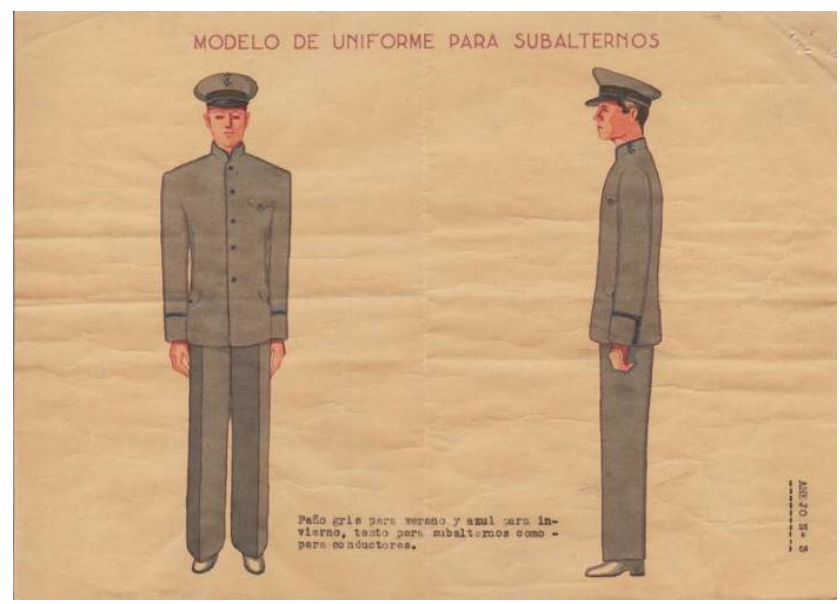

Fig. 2.- Modelo de uniforme para subalternos, según estableció la circular núm.

13, 1941 (Fuente: AHL, Lérida). 


\section{LOS SERVICIOS CENTRALES DEL INC EN MADRID}

Los Servicios Centrales del INC se ubicaron desde el inicio en Madrid. En un primer momento, la Jefatura Central -dado que así se denominó en esta etapa inicial- se emplazó en la calle Almagro, núm. 42. Sin embargo, pronto se vio la necesidad de adquirir un nuevo edificio con destino exclusivo para oficinas centrales del INC, por lo que en 1941 comenzaron las gestiones para alcanzar su consecución ${ }^{7}$.

Así, el 17 de noviembre de 1942 se fundó la nueva sede de las oficinas centrales, que se ubicaron en la avenida del Generalísimo, núm. 31 -actual paseo de la Castellana ${ }^{8}$, en un pequeño palacete del siglo XIX que había pertenecido a los condes de San Bernardo (figuras 3-5). La inauguración de los nuevos locales tuvo lugar el 16 de noviembre de 1942, a las 20:30 horas, con la asistencia de varias personalidades políticas, entre las que figuraba el ministro de Agricultura, Miguel Primo de Rivera; el director general de Colonización, Ángel Zorrilla; y diferentes cargos del Ministerio de Agricultura y del $\mathrm{INC}^{10}$.

7 «Instituto Nacional de Colonización. Adquisición de edificio», $A B C$, Madrid, sábado 27 de septiembre de 1941, p. 2.

8 Desde 1949, parte del paseo de la Castellana -concretamente el tramo existente antes de la guerra civil- recuperó su nombre. Por este motivo, en la documentación del INC encontramos las direcciones de avenida del Generalísimo, núm. 31 y paseo de la Castellana, núm. 31 .

9 El palacio de los Condes de San Bernardo, que albergó la sede del INC en Madrid, fue derribado en 1971. En la actualidad, en su lugar se levanta la sede del Banco de Valencia. DELGADO, A., "Los palacios perdidos de la Castellana", $A B C$, Madrid, sábado 25 de mayo de 2013, pp. 58-59.

Para profundizar en este tema, véase también AZORÍN, F. y GEA, M. I., La Castellana, escenario de poder. Del palacio de linares a la Torre Picasso, Madrid, Ediciones La Librería, 1990; GONZÁLEZ-VARAS, I., Los palacios de la Castellana. Historia, arquitectura y sociedad, Madrid, Turner, 2010.

10 «El ministro de Agricultura preside la inauguración del Instituto de Colonización», $A B C$, Madrid, martes 17 de noviembre de 1942, p. 11. 


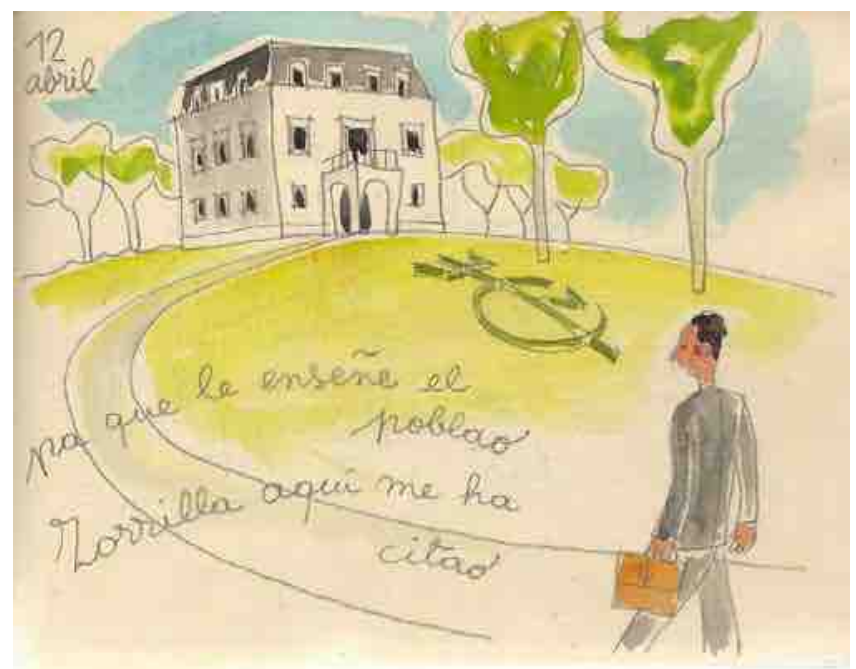

Fig. 3.- Visita de José Borobio a la sede de Colonización en la antigua avenida del Generalísimo, núm. 31 (actual paseo de la Castellana), el 12 de abril de 1944 (Fuente: Archivo de la familia Borobio, Zaragoza).
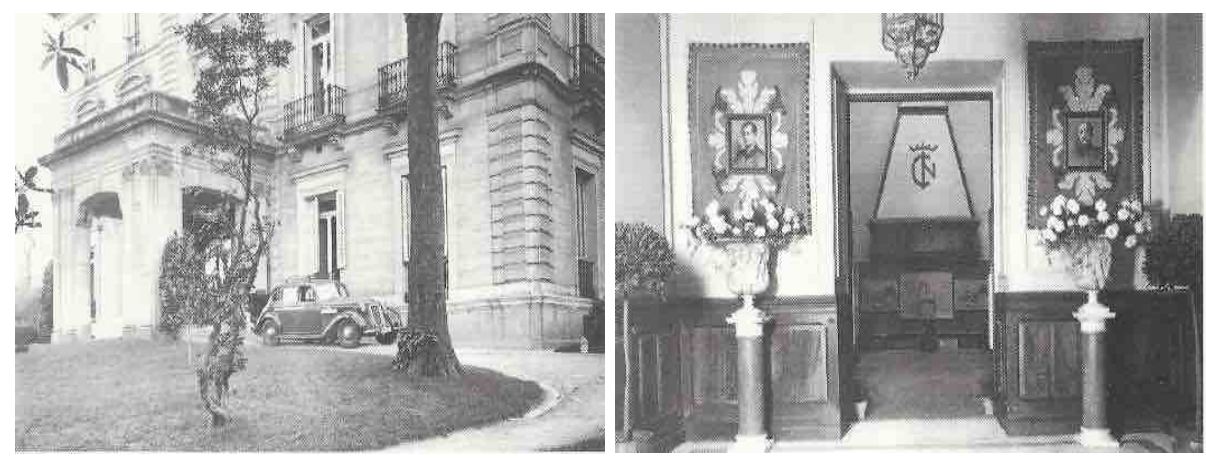

Figs. 4 y 5. Sede Central del INC, en la avenida del Generalísimo, núm. 31, hacia 1942, posiblemente el día de su inauguración (Fotos: GÓMEZ BENITO y GIMENO, 2003: 46).

Después, el 15 de mayo de 1947, con motivo de la institución de San Isidro Labrador como patrono del Instituto, se instaló una imagen del santo en los 
jardines de la sede central. Por este motivo, se procedió a la bendición de los locales y la entronización y bendición de la talla del santo, ejecutada por el escultor José Luis Sánchez ${ }^{11}$ (figura 6).

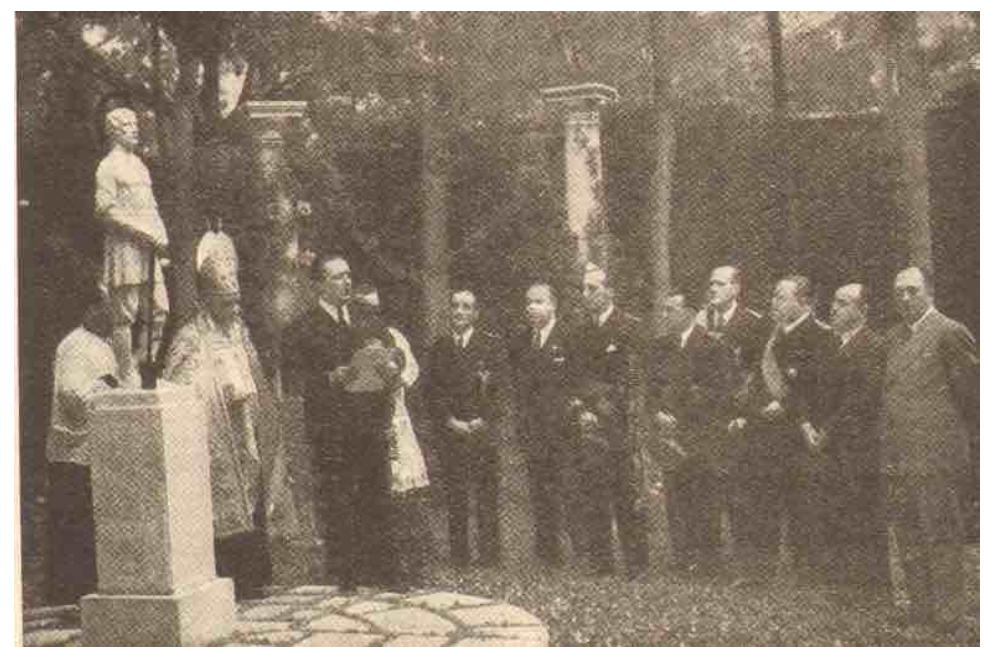

Fig. 6. Entronización de la imagen de San Isidro en el edificio central del Instituto Nacional de Colonización, 15 de mayo 1947 (Fuente: Agricultura).

Pero la actividad del Instituto fue creciendo (y con ella su plantilla), motivo por el cual en 1948 se proyectó, por el director del Servicio de Arquitectura del INC, José Tamés Alarcón, un nuevo edificio, que se emplazaría en el número 2 del paseo del Generalísimo -en la actualidad, paseo de la Castellana, núm. $112^{12}$ - esquina con la calle Joaquín Costa. Su construcción sufrió cierto retraso, siendo terminadas las obras en el año $1956^{13}$, pasando a convertirse en la sede Central del INC durante el resto de su trayectoria (figuras 7-8).

11 "La fiesta de la colonización. Bendición de los locales del Instituto Nacional de Colonización”, Agricultura. Revista agropecuaria. Suplemento de Colonización, núm. 6, Madrid, junio de 1947, p. 40; «La fiesta de San Isidro», $A B C$, Madrid, jueves 15 de mayo de 1947, p. 10.

12 El edificio se conserva en la actualidad, habiendo sido la sede de la Dirección General de Arquitectura, Vivienda y Suelo, dependiente del Ministerio de Fomento, aunque recientemente ha quedado en desuso.

13 Archivo Histórico Provincial de Lérida (AHL), Sección INC, Caja 72. 
Este inmueble se adaptó a las necesidades de las secciones del Instituto y sus diferentes servicios. Su entrada principal estaba dispuesta en la calle Joaquín Costa, a la que se tenía acceso a través de un jardín, y por ella se estableció el paso de vehículos hasta el patio central del edificio. La entrada general de empleados, por otra parte, se situó en la avenida del Generalísimo. Contaba entre sus dependencias con sala de Consejos, salones de actos y de exposiciones, despachos y locales auxiliares (como archivos técnicos y administrativos, laboratorios, talleres, garaje, almacenes, restaurante, locales de cultura y deporte para los empleados $)^{14}$. Además, en el jardín central se dispuso una escultura de San Isidro, que había sido designado patrón del Instituto Nacional de Colonización en $1947^{15}$. Para ello, se convocó en 1952 un concurso entre escultores, del que resultó ganador el artista Antonio Cano Correa.

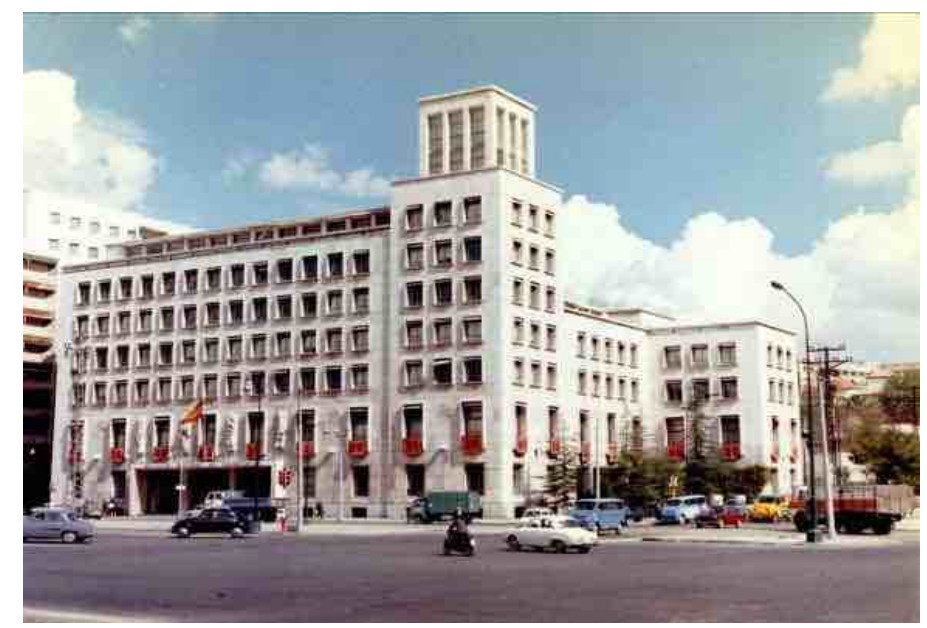

Fig. 7.- Edificio central del Instituto Nacional de Colonización, hacia 1970

(Foto: MAPAMA, Mediateca, Madrid).

14 P. C. Z., «El nuevo edificio del Instituto de Colonización: una notable realización del arquitecto D. José Tamés Alarcón», $A B C$, Madrid, viernes 3 de agosto de 1956, pp. 10-11.

15 Hay que señalar asimismo que en 1940 ya se había declarado al santo madrileño patrón de la Agricultura, pero posteriormente, en 1947, se le declaró también patrón del Instituto Nacional de Colonización. «San Isidro Labrador, patrón de la Agricultura», Amanecer, Zaragoza, martes 2 de enero de 1940, p. 3; «Decreto de 28 de marzo de 1947 por el que se instituye la Fiesta de Colonización, que se celebrará el día 15 de mayo de cada año, festividad de San Isidro, bajo cuya advocación se coloca el Instituto Nacional de Colonización», Boletín Oficial del Estado, núm. 107, jueves 17 de abril de 1947, pp. 2.260-2.261. 


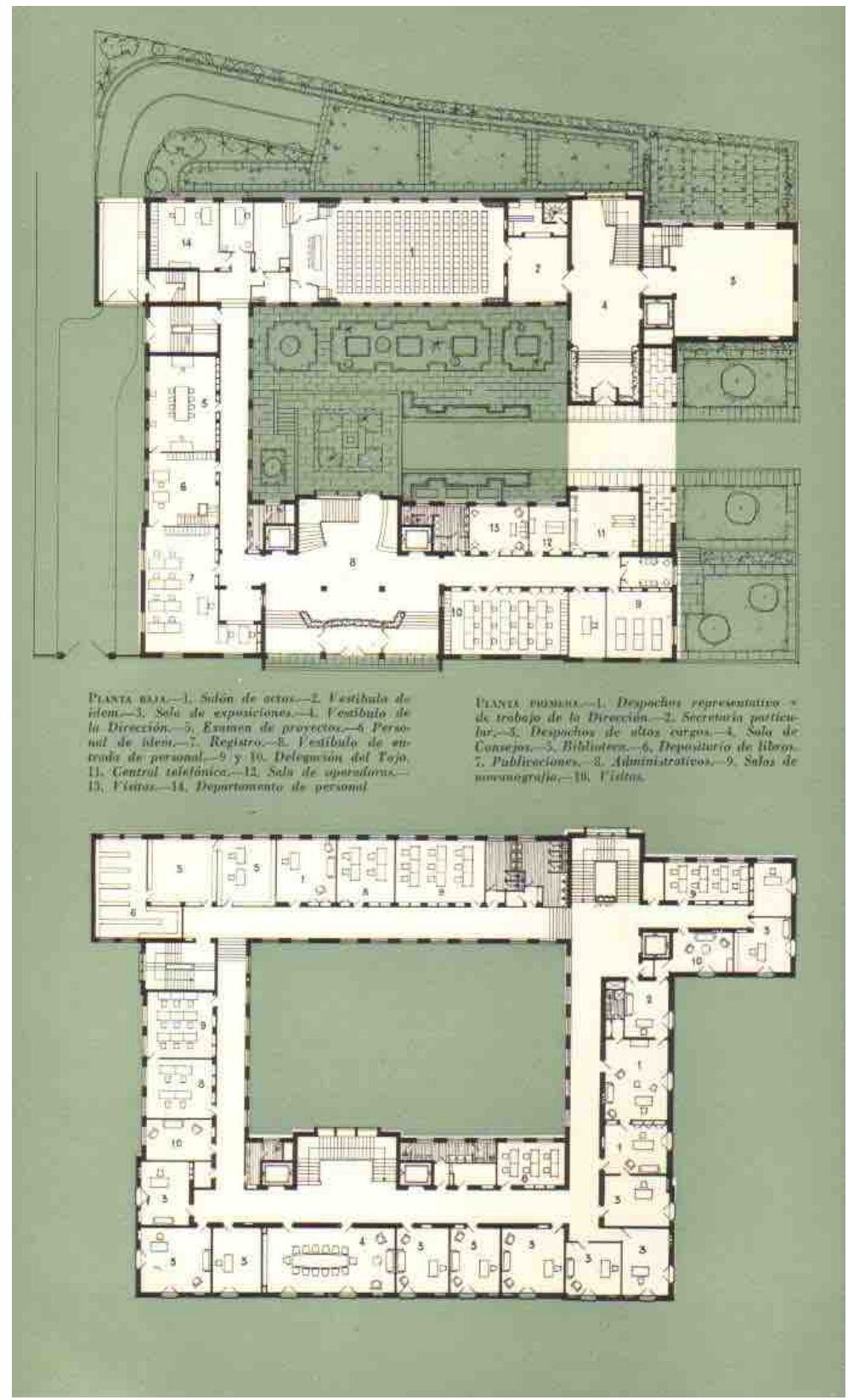

Fig. 8.- Plantas baja y primera del edificio central del Instituto Nacional de Colonización, 1956 (Fuente: RNA). 
También participaron en su decoración otros artistas plásticos, como los escultores Ángel Ferrant, autor de los cuatro altorrelieves de la fachada a la avenida del Generalísimo - que representan las estaciones del año- y Eduardo Carretero, a quien se deben los bajorrelieves con motivos florales y cultivos situados entre los balcones de la planta principal. Así como los pintores Amadeo Gabino, creador de los dos grupos murales de la entrada; Manuel Rivera, de las pinturas de la escalera de Dirección ${ }^{16}$; y José Lapayese, autor del mapa de España que ocupaba uno de los frentes de la sala de Consejos $^{17}$ (figura 9).

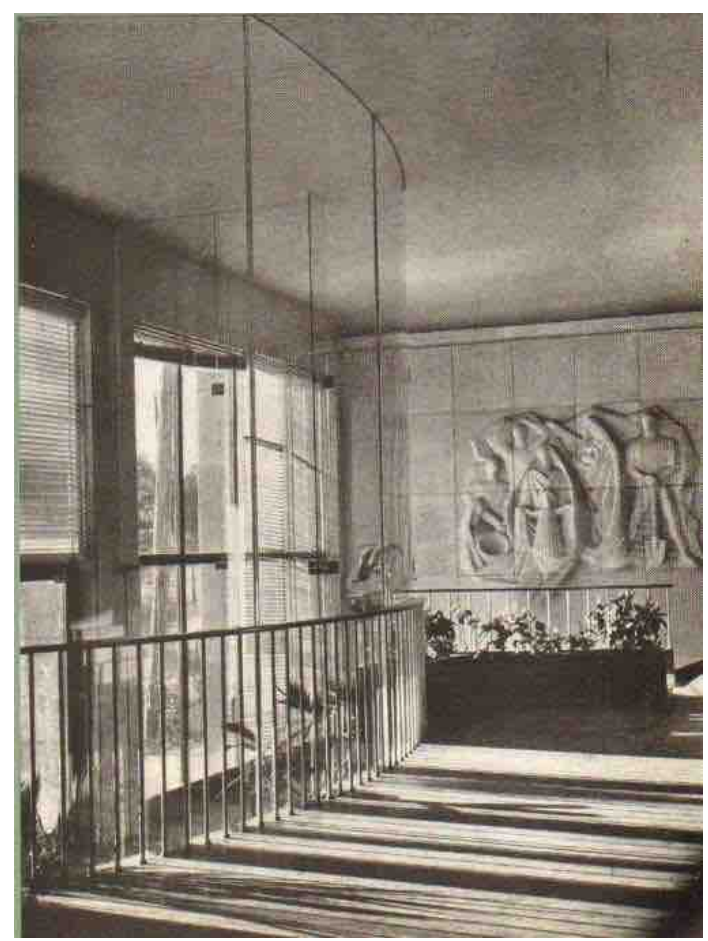

Fig. 9.- Vista parcial del vestíbulo de personal del edificio central del Instituto Nacional de Colonización, 1956 (Fuente: RNA).

16 Sobre la labor de Rivera en el INC, véase: BAZÁN DE HUERTA, M., "Rivera antes de Rivera. Los trabajos pictóricos de Manuel Rivera para el Instituto Nacional de Colonización", Arte y Ciudad-Revista de investigación, núm. 9, Madrid, Grupo de Investigación Arte, Arquitectura y Comunicación en la Ciudad Contemporánea, Universidad Complutense de Madrid, abril de 2016, pp. 61-90.

17 TAMÉS ALARCÓN, J., "Edificio Social del Instituto Nacional de Colonización en Madrid", Revista Nacional de Arquitectura, núm. 178, Madrid, Colegio Oficial de Arquitectos, octubre de 1956, pp. 7-16. 


\section{LA SEDE DE LA DELEGACIÓN REGIONAL DEL EBRO EN ZARAGOZA}

La actividad desarrollada por el INC en la zona objeto de nuestro estudio se desarrolló a través de la Delegación Regional del Ebro, que tenía su sede en Zaragoza. Desde esta ciudad se llevaron a cabo los trabajos relacionados con las zonas de la cuenca del río Ebro, contando además con una oficina provincial en la ciudad de Lérida, como analizaremos posteriormente. Esta Delegación, como estudiaremos a continuación, no llegó a tener un edificio propio construido expresamente para este fin, por lo que, a lo largo de su historia, se constatan varios cambios de domicilio.

La circular interna núm. 13 del INC, de 16 de septiembre de 1941, que, como hemos indicado anteriormente, estableció las normas relativas al régimen de residencias y alquiler de locales para las jefaturas de Brigada, señaló lo siguiente:

" 1 '.- En tanto se construyan edificios adecuados en las zonas para instalación de oficinas de las distintas Brigadas, cada una de las de Trabajo y Explotación tendrá en general dos residencias, una OFICIAL en capital o población de importancia y otra de TRABAJO en punto próximo al centro de actividad de la zona o finca" 18 .

En consecuencia a lo expuesto, se instituyó la Brigada de Información del Ebro, con residencia oficial en Zaragoza, y las Brigadas de Trabajo del Canal de Aragón y Cataluña, con sede oficial y de trabajo en Lérida; y del delta del Ebro, con residencia oficial en Tortosa y de trabajo en Amposta. Aunque en estos momentos, como apuntó Francisco de los Ríos, todavía se estaba configurando el INC:

“Aquel organismo, andando el tiempo, se transformaría en Instituto Nacional de Colonización. Pero al principio, cuando llegué [en 1941], no tenía un fin específico, sólo el exclusivo de recibir información. Los ingenieros que allí nos juntamos, en la calle de Canfranc, no sabíamos que hacer" ${ }^{\text {"19 }}$.

Es preciso mencionar también la existencia de otras oficinas de trabajo instaladas más tarde -y de forma temporal- en algunos de los núcleos de colonización como es el caso de Ontinar del Salz o San Jorge, en la zona de la Violada (Zaragoza-Huesca), o varias residencias para el personal facultativo del INC,

18 AHPZ, Sección INC, Caja A/39895, Circular interna del Instituto Nacional de Colonización núm. 13: "Residencias y alquiler de locales para las Jefaturas de Brigada", 16 de septiembre de 1941.

19 ZAPATER, A., "Ha visto nacer 36 pueblos: Francisco de los Ríos, una vida dedicada a los riegos de Aragón", publicado en 1988 en Heraldo de Aragón, Zaragoza, recogido en DE LOS RÍOS ROMERO, F., Cuarenta años de testimonio público por las gentes del campo, Zaragoza, Universidad de Zaragoza, Facultad de Ciencias, Cátedra de Hidrogeología, 1990, pp. 214-217. 
como la de la finca Paridera Alta y Baja, junto a El Temple (Huesca), la de Gimenells (Lérida), la de Figarol (Navarra), la de Sariñena (Huesca) o la de Valareña (Zaragoza).

Posteriormente, en junio de 1942, se crearon las Delegaciones Regionales (entre ellas, la del Ebro) y las Delegaciones Provinciales o Locales (como las de Tortosa, Lérida y Zaragoza), cuyos cometidos quedaron establecidos en la circular interna núm. 54, de 7 de julio del mismo año. De este modo, las Regionales serían las encargadas de realizar las tareas de las anteriores Brigadas de Información, y tendrían que seguir el desarrollo del Plan Nacional de Obras Hidráulicas en la región, con el fin de acomodar al mismo las propuestas de declaración de zonas de interés nacional. También debían de estar en contacto directo con el campo para conocer las dificultades de los agricultores y estudiar los problemas de la colonización, entre otras cuestiones; así como establecer un plan de actuación en las diferentes áreas, siempre supeditados al ritmo de las obras hidráulicas.

Además, en su décimo punto, esta circular precisaba que "las Delegaciones Regionales actuarán con absoluta independencia administrativa de las restantes Delegaciones establecidas en la región, aún en el caso de estar instaladas en el mismo local"20. De este modo, a la Delegación Regional del Ebro estarían adscritas las Delegaciones de Lérida, Zaragoza y Tortosa.

En cuanto a las Delegaciones Provinciales o Locales, cabe decir que tenían asignadas funciones fundamentalmente ejecutivas, previamente ordenadas por la Dirección General, como la redacción de Proyectos Generales y Ordinarios de Colonización; la dirección técnica y administrativa de las explotaciones de fincas del INC o la ejecución de las obras. Además, actuaban con independencia administrativa de las Delegaciones Regionales ${ }^{21}$.

Como hemos indicado anteriormente, la Delegación Regional del Ebro tuvo su domicilio en Zaragoza y no dispuso de un edificio construido expresamente para este fin, pese a ser una de las delegaciones más importantes del Instituto. De ahí que, en función de las necesidades, fuera cambiando de

20 AHPZ, Sección INC, Caja A/39895, Circular interna del Instituto Nacional de Colonización núm. 54: "Delegaciones", 7 de julio de 1942.

21 "Las Delegaciones, que llevan el nombre de la localidad donde radican, actuarán con absoluta independencia administrativa de las Delegaciones Regionales, aún en el caso de estar instaladas en el mismo local". AHPZ, Sección INC, Caja A/39895, Circular interna del Instituto Nacional de Colonización núm. 54: "Delegaciones", 7 de julio de 1942. Por citar algún ejemplo, por resolución de la Dirección General del INC de fecha 3 de marzo de 1953 se creó la Delegación de zona en la ciudad de Cáceres, por no poder atender la zona adecuadamente desde Talavera de la Reina, a la que pertenecía en ese momento esta provincia, siendo designado como jefe de esta el ingeniero agrónomo José María García Pérez. 
emplazamiento a lo largo de su existencia, recurriéndose a locales arrendados para este destino.

Por su parte, la primera sede de la denominada "Brigada de Información del Ebro del Instituto Nacional de Colonización" - de la que tenemos constancia documental desde el año $1940^{22}$-, estuvo, en primer lugar, ubicada en el domicilio particular de su primer director, el ingeniero agrónomo Pedro Mela Mela - paseo Marina Moreno 31, en la actualidad denominado paseo de la Constitución-, y después en las calles Bolonia 10, principal izquierda ${ }^{23}$, y la de Canfranc, núm. $2^{24}$. En este momento, de la Brigada de Información del Ebro dependían las Delegaciones de Trabajo e Información de Zaragoza, de Tortosa -que se ocuparía de la zona del delta del Ebro- ${ }^{25}$ y de Lérida.

En 1945, tenemos constancia de un cambio en la dirección de esta Delegación, esta vez con domicilio en el paseo General Mola, núm. 2 (hoy paseo de Sagasta $)^{26}$. El edificio donde se ubicó, denominado Edificio Elíseos, tenía acceso desde la avenida General Mola, núms. 2 y 4, y desde la avenida Calvo Sotelo, núm. 3 (actualmente paseo de la Gran Vía), y había sido proyectado por el arquitecto zaragozano Teodoro Ríos Balaguer en 1939, siendo financiado por la entidad bancaria Caja de Ahorros y Monte de Piedad de Zaragoza (figura $10)^{27}$. Al aumentar la plantilla de la Delegación, su ingeniero jefe solicitó, en diciembre de 1947, al director general de Colonización que les autorizase el

22 El documento más antiguo conservado por esta Brigada que se ha localizado en el Archivo Histórico Provincial de Zaragoza, con el número 1 de expediente, aparece fechado en agosto de 1940. AHPZ, Sección INC, Caja A/25164, Exp. 1: «Informe previo de la zona», Zaragoza, agosto de 1940. No obstante, de estos primeros años apenas se ha conservado documentación. El primer libro de registro localizado comienza el 3 de enero de 1942 .

23 Desde el 5 de enero de 1942 se ha constatado documentalmente el pago del alquiler del local de oficinas. AHPZ, Sección INC, Lib. A/41150, "Mayor auxiliar. Delegación Regional del Ebro. Delegación de Tortosa".

24 Durante la elaboración de este estudio ha aparecido nueva documentación referente a la Delegación Regional del Ebro, hecho que ha permitido precisar parte de los datos aquí recogidos. Sin embargo, todavía falta parte de la documentación, por lo que es posible que en un futuro se puedan aportar datos más concretos.

25 AHL, Sección INC, Caja 9. La oficina de esta Delegación cesó su actividad en diciembre de 1949, por considerarse innecesaria. AHPZ, Sección INC, Caja A/39929, Exp. Varios.

26 Hasta la fecha no hemos podido localizar información en la que se precise el momento exacto del cambio de domicilio de la Delegación.

27 Para profundizar en la historia constructiva de este edificio, véase ALDAMA FERNÁNDEZ, L., "El edificio Elíseos de Zaragoza: un ejemplo de la arquitectura monumental de Teodoro Ríos Balaguer", Artigrama, núm. 21, Zaragoza, Departamento de Historia del Arte de la Universidad de Zaragoza, 2006, pp. 633-654. La autora establece como posible fecha de terminación de este inmueble el año 1945. Véase también RÍOS, T., "Bloque de tres casas en la plaza del Paraíso", Revista Nacional de Arquitectura, núm. 95, Madrid, Colegio Oficial de Arquitectos, noviembre de 1949, p. 493; MARTÍNEZ HERRANZ, A., Los cines en Zaragoza: 1939-1979, Zaragoza, Elazar ediciones, 2005, pp. 6273. 
alquiler de un nuevo local accesorio, o el traslado de toda la Delegación a un inmueble más amplio ${ }^{28}$.

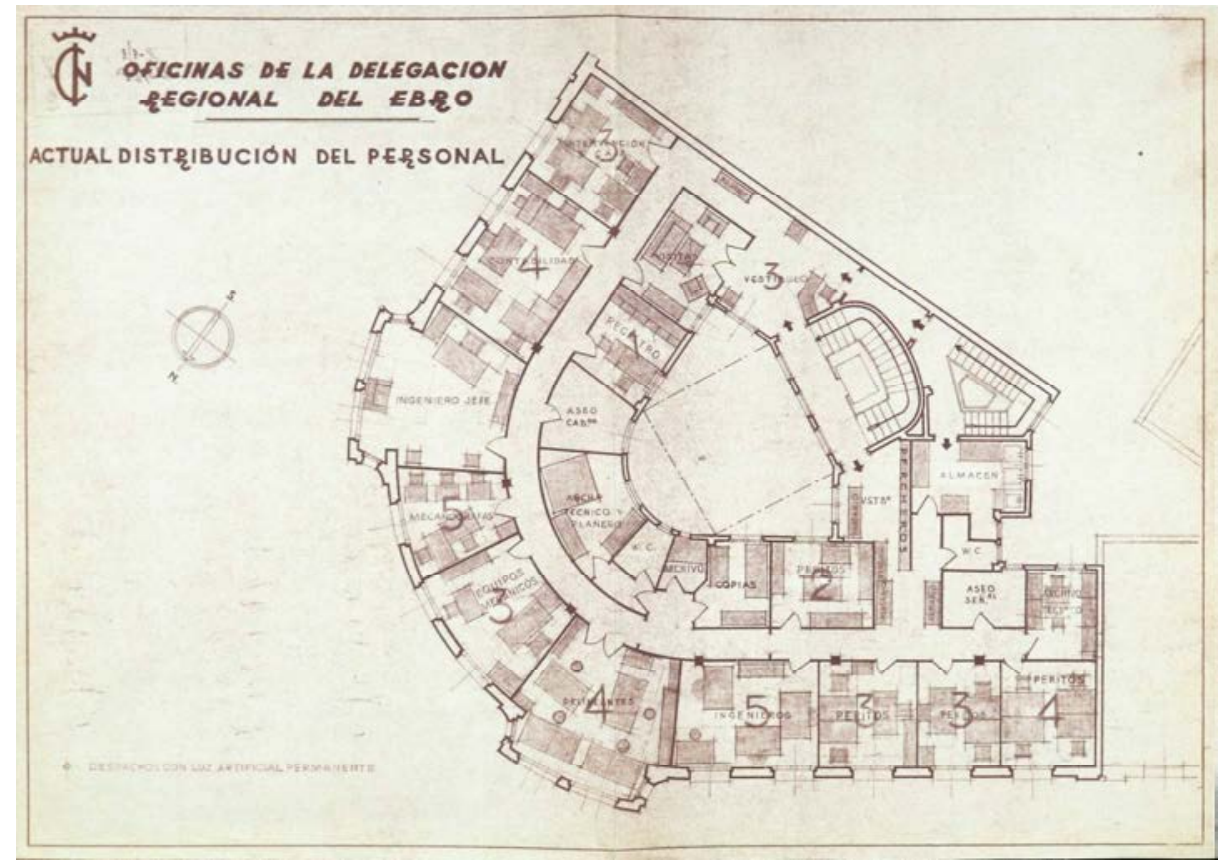

Fig. 10. Planta de distribución de las oficinas de la Delegación en la sede del paseo General Mola, núm. 2, 1949 (Fuente: AHPZ, Zaragoza).

Sin embargo, la Delegación se mantuvo en el mismo emplazamiento, por lo que, en 1949, y como resultado del aumento de trabajo y el consecuente crecimiento de personal de esta plantilla, se pidió de nuevo una ampliación de locales. Por este motivo, en febrero de 1949 el ingeniero jefe de la Delegación envió a la Dirección General un informe relativo a la instalación de las oficinas de Zaragoza, en el que daba cuenta de su situación y de las condiciones en que estaban desarrollando su trabajo (figura 10):

"Esta es pues la situación actual de estas oficinas, que como puede verse resulta agobiante e insostenible por más tiempo, por lo cual y tratando de resolver este problema hemos realizado diversas gestiones 
en busca de pisos o edificios que reúnan mejores condiciones de amplitud"29.

En dicho documento se plasmaba la insuficiencia de espacio para albergar a todo el personal, que estaba integrado por 43 miembros, así como la inadecuada distribución de las estancias: jefe e ingenieros agrónomos (7), ingeniero de montes (1), arquitecto (1), veterinario (1), peritos agrícolas (10), aparejadores (2), ayudante de montes (1), administrativos (8), delineantes (6) y auxiliares taquimecanógrafos (6).

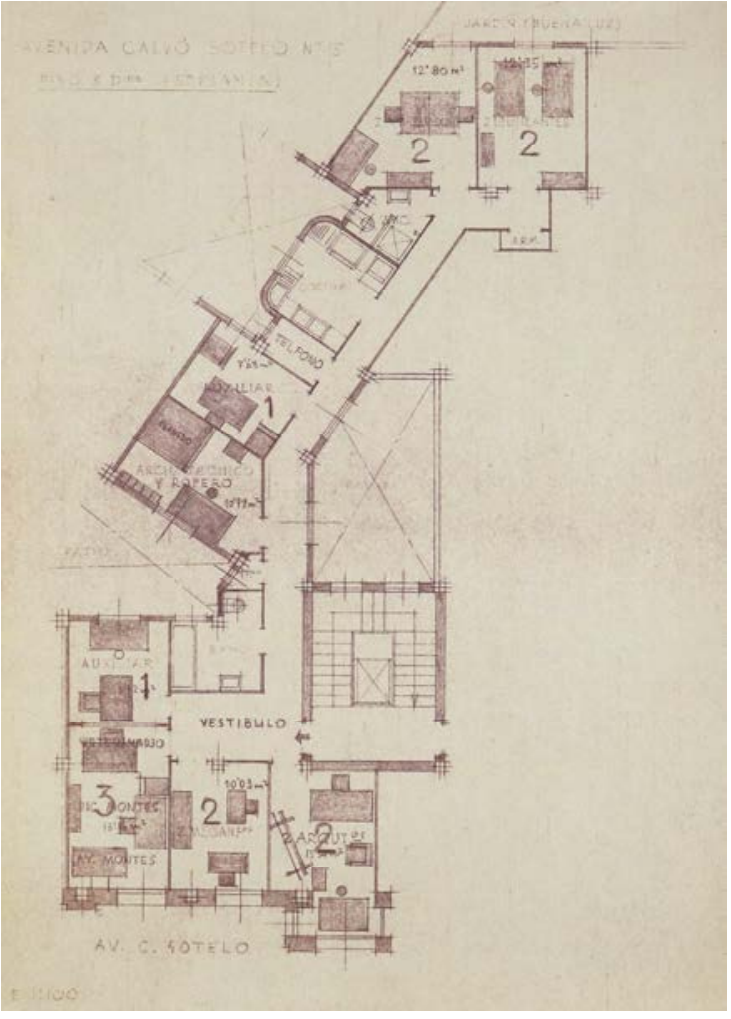

Fig. 11. Planta de distribución de las oficinas de la Delegación en la sede de la Avenida Calvo Sotelo, núm. 3, 1954 (Fuente: AHPZ, Zaragoza).

En este mismo informe se proponían tres soluciones posibles a este problema: en primer lugar, adquirir la planta de entresuelo del edificio que en ese momento estaba construyendo la empresa CIUVASA en la zona de Miraflores; en segundo lugar, comprar o alquilar tres viviendas (una planta y media) de una casa recién edificada por la empresa Construcciones S.L., en Miraflores, y que además ofrecía a la Delegación la posibilidad de construir un nuevo portal con entrada autónoma, con el objetivo de que el servicio de oficinas quedara completamente independiente del resto de las viviendas; $\mathrm{y}$, en tercer lugar, la adquisición o arriendo del chalet de cuatro pisos (tres plantas y semisótano) propiedad del Sr. Moliner en el paseo General Mola, cerca de la sede de la Confederación Hidrográfica del Ebro. Esta última era la opción considerada más adecuada por la

29 AHPZ, Sección INC, Caja A/39956, Exp. Varios. 
Delegación para el establecimiento de sus nuevas oficinas, dado que así sus servicios quedarían integrados en un solo edificio.

Pero el INC no accedió a esta propuesta, y finalmente se decidió ampliar las oficinas existentes con otros locales auxiliares. Por este motivo, en noviembre de 1949 se autorizó a la Delegación a alquilar un piso en la avenida Calvo Sotelo, núm. 3, $3^{\circ}$ derecha, es decir, en la otra fachada del Edificio Elíseos, lo que facilitaría la unión de los dos espacios ${ }^{30}$. De este modo, se realizaron las pertinentes gestiones para conseguir que los propietarios del piso $2^{\circ}$ de este mismo domicilio les cedieran una habitación de su vivienda con el fin de construir una escalera que enlazara las dos oficinas, lo que no fue posible. Tampoco se pudo llegar a un acuerdo con el dueño del piso $3^{\circ}$ con fachada al paseo $\mathrm{Ge}-$ neral Mola, por lo que el arquitecto de la Delegación, José Borobio ${ }^{31}$, estudió la comunicación de estos dos espacios mediante la construcción de una escalera adosada al muro del patio interior de luces, abriendo una pequeña puerta en la pared del piso de Calvo Sotelo, obra que fue aprobada por la entidad propietaria del inmueble ${ }^{32}$.

Además, en esta misma fecha de 1949 se suprimieron las oficinas de la Delegación del INC en Tortosa, por lo que se decidió que los muebles y enseres existentes en ella se usaran para la dotación de las nuevas oficinas de Zaragoza ${ }^{33}$. Así, en enero de 1950, parte de los servicios de la Delegación Regional del Ebro ya estaban instalados en la calle Calvo Sotelo, núm. $3,3^{\circ}$ derecha $^{34}$ (figura 11).

30 Ídem.

31 Como ya señalamos, la circular núm. 112 del INC estableció que la conservación de los edificios de la Delegación y las reparaciones a realizar en ellos estarían a cargo del arquitecto encargado de la Delegación.

32 AHPZ, Sección INC, Caja A/39956, Exp. Varios.

33 Ídem.

34 AHL, Sección INC, Caja 40. 


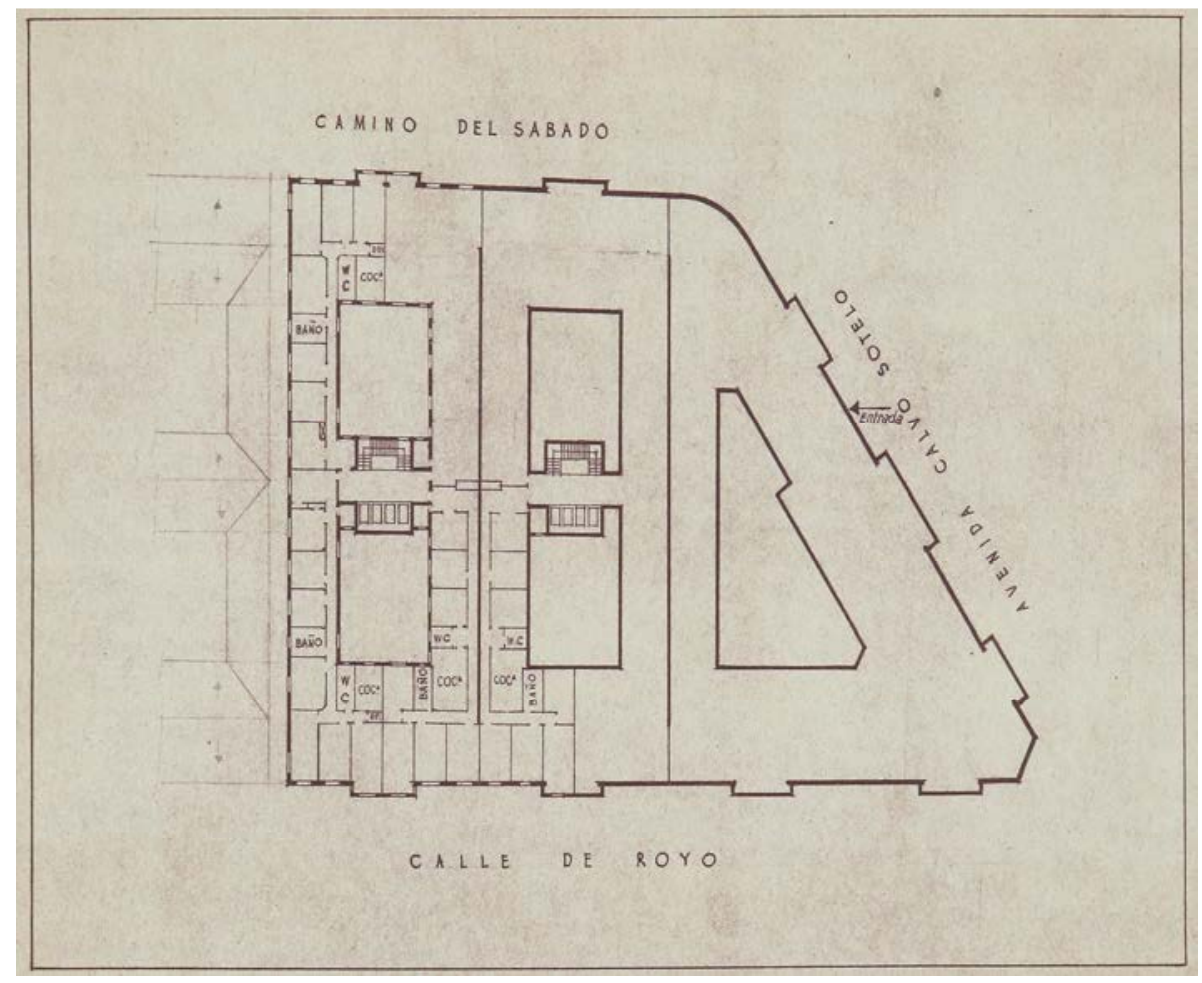

Fig. 12. Planta de distribución del edificio propuesto para alojar las oficinas de la Delegación en la Avenida Calvo Sotelo, núm. 11, 1954 (Fuente: AHPZ, Zaragoza).

Así, en marzo de 1954 se redactó un informe relativo a la instalación de las oficinas de la Delegación Regional del Ebro, planteando dos soluciones: la primera, consistente en la situación de estas en el edificio construido por el Banco de Aragón situado en la calle del Coso núms. 36-40; y, la segunda, en la adquisición de las viviendas de las plantas $7^{\mathrm{a}}$ y $8^{\mathrm{a}}$ del bloque de viviendas que estaba construyendo la Inmobiliaria Calvo Sotelo S.A. en el número 11 de la avenida homónima (actualmente denominada paseo de la Gran Vía) (fig. 12). 


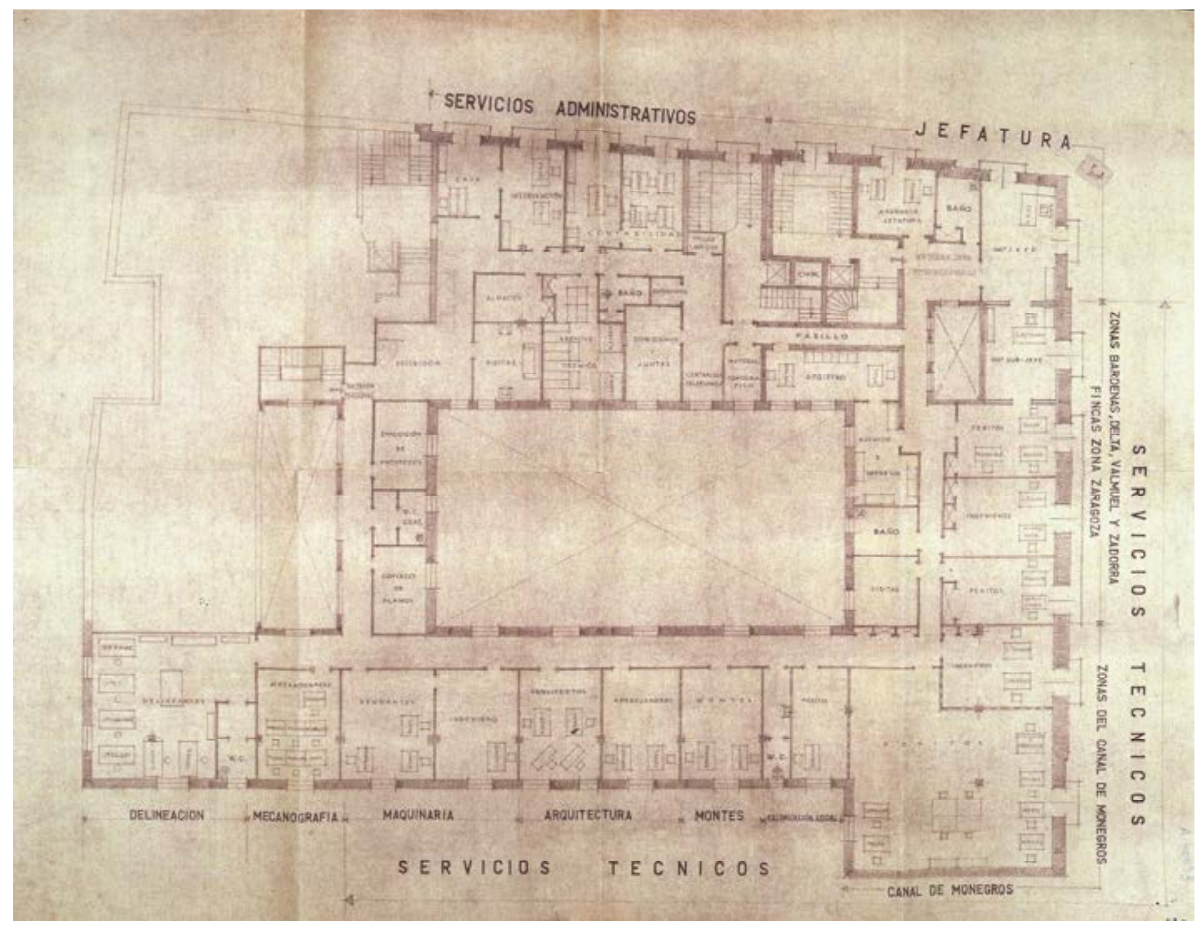

Fig. 13. Planta de distribución de las oficinas de la Delegación en la sede de la calle Teniente Coronel Valenzuela, núm. 5, 1954 (Fuente: AHPZ, Zaragoza).

Incluso se planteó una tercera alternativa consistente en la instalación de las oficinas en el palacio de la finca de La Alfranca (Pastriz, Zaragoza), propiedad del INC. Pero su situación fuera de la ciudad de Zaragoza, con el consecuente traslado del personal y de las visitas a las oficinas, desaconsejaron esta idea, decantándose por la primera ${ }^{35}$.

Seguidamente, el 22 de octubre de 1954, se produjo un nuevo traslado por motivos de espacio, en este caso a la calle Teniente Coronel Valenzuela, núm. $5^{36}$, por tanto, siempre buscando emplazamientos importantes y céntricos a nivel urbano (figura 13). Este inmueble, cuya fachada principal se encuentra en

35 AHPZ, Sección INC, Caja A/40093, Exp. Material.

36 Para profundizar en el análisis urbanístico de esta calle, véase YESTE NAVARRO, I., La reforma interior. Urbanismo zaragozano contemporáneo, Zaragoza, Institución «Fernando el Católico», 1998, pp. 223-238. 
la calle del Coso, núms. 36-40, fue construido por el Banco de Aragón ${ }^{37}$, dado que aquí se situó la casa matriz de dicha entidad. El edificio, proyectado por el arquitecto madrileño Julián Laguna Serrano, se emplazó en el solar que había ocupado en su día la casa de la familia Pignatelli ${ }^{38}$.

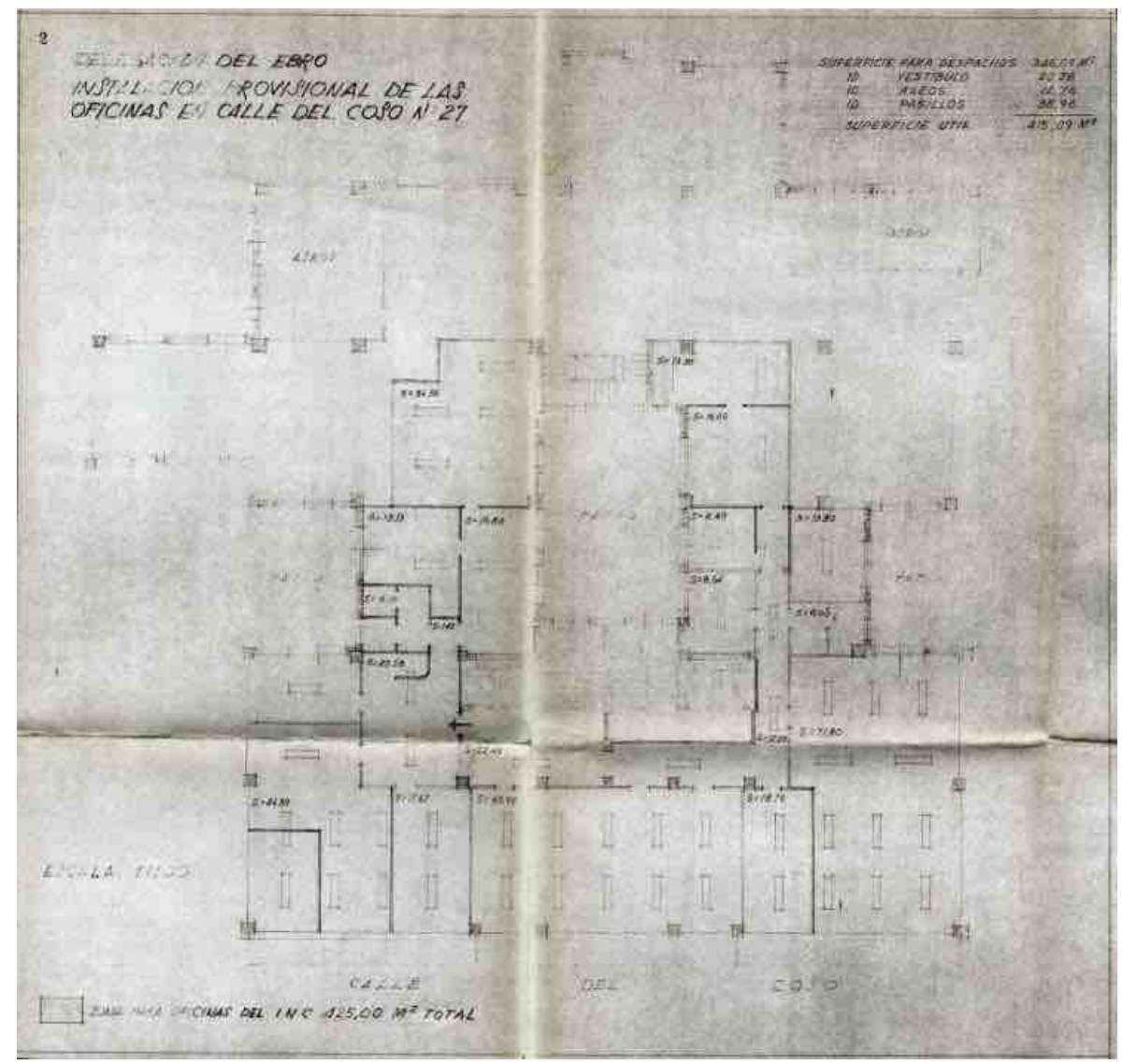

Fig. 14. Planta de distribución de las oficinas provisionales de la Delegación en la calle del Coso, núm. 27, según plano del año 1970 (Fuente: AHPZ, Zaragoza).

37 BLANCO GARCÍA, J., El Banco de Aragón, Zaragoza, Delegación del Gobierno en Aragón, 2004.

38 LABORDA YNEVA, J., Zaragoza. Guía de arquitectura, Zaragoza, Caja de Ahorros de la Inmaculada de Aragón, 1995, p. 187. 

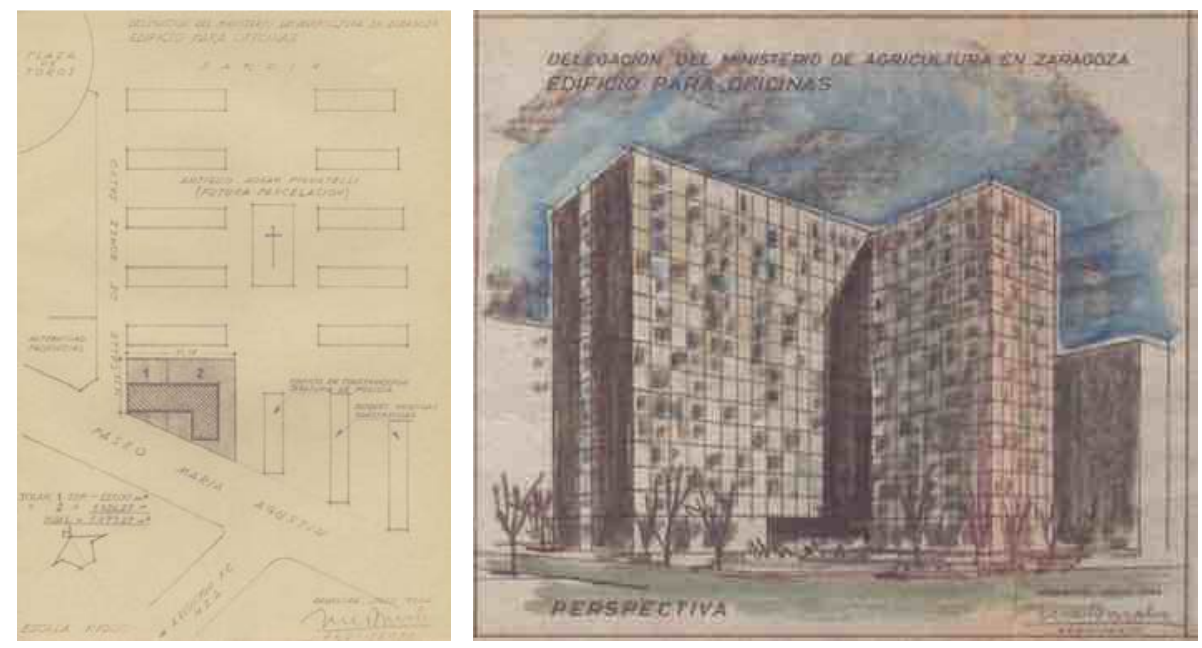

Figs. 15 y 16. Plano de situación y perspectiva del edificio para las oficinas del Ministerio de Agricultura en Zaragoza, 1964 (Fuente: AHPZ, Zaragoza).

Para ello fue necesario acometer las correspondientes obras de reforma, dado que la planta principal del edificio que ocuparía la sede de la Delegación estaba distribuida en ese momento en tres viviendas y cinco oficinas, siendo necesario comunicar los distintos espacios. Las obras de reforma y acondicionamiento de los locales, ejecutadas por la empresa Construcciones Joaquín Herrero, comenzaron el 7 de junio de 1954. La inauguración de este inmueble de nueva construcción tuvo lugar el 29 de junio de $1951^{39}$.

Estos locales se vieron complementados con el alquiler de otro espacio en la inmediata calle del Coso, núm. 27, donde se instalaron unas oficinas auxiliares "provisionales" 40 (figura 14). Este domicilio se encontraba en el mismo edificio en que estaba ubicado el conocido comercio "Bazar X"41.

39 Para profundizar en esta cuestión, véase «Las reformas urbanas», Heraldo de Aragón, Zaragoza, martes 31 de diciembre de 1940, p. 4; P. R., «En medio siglo Zaragoza ha cambiado su fisonomía urbana, para convertirse en una gran capital», Heraldo de Aragón, Zaragoza, domingo 1 de enero de 1950, p. 7; «El Banco de Aragón inauguró ayer su nuevo y grandioso edificio», Heraldo de Aragón, Zaragoza, sábado 30 de junio de 1951, p. 3; «El Banco de Aragón abre hoy sus nuevas oficinas», Hoja oficial del Lunes, Zaragoza, lunes 2 de julio de 1951, p. 9.

40 Asimismo, en 1962 se alquiló un local para ubicar el Archivo Técnico de la Delegación del Ebro, que se situó en la calle Juan José Rivas núm. 9. AHPZ, Sección INC, Caja A/40004, Exp. Material.

41 VÁZQUEZ ASTORGA, M., Cafés de Zaragoza. Su biografia, 1797-1939, Zaragoza, Institución «Fernando el Católico». Excma. Diputación de Zaragoza, 2015, p. 111. 
Pero el problema de la sede del INC en Zaragoza todavía no se había solucionado. De hecho, la Delegación de Zaragoza quería construir un nuevo edificio para alojar todas sus oficinas, "ya que en la actualidad se encuentran mal acondicionadas". Por este motivo, se realizaron gestiones con la Diputación Provincial de Zaragoza para conseguir la enajenación de un terreno de su propiedad en el paseo de María Agustín -esquina con la calle Vicente Gómez Salvo-, junto al edificio del Hogar Pignatelli y al inmueble de la Jefatura de Policía $^{42}$. Así, en diciembre de 1963 se consiguió la autorización del Ministerio de la Gobernación para que la Diputación enajenara el solar número 2 de la parcelación del Hogar Pignatelli. La urbanización de estos terrenos, denominados "del Hospicio", habían comenzado en diciembre de $1955^{43}$. Fue, por tanto, en este emplazamiento donde se planeó la construcción de esta nueva sede.

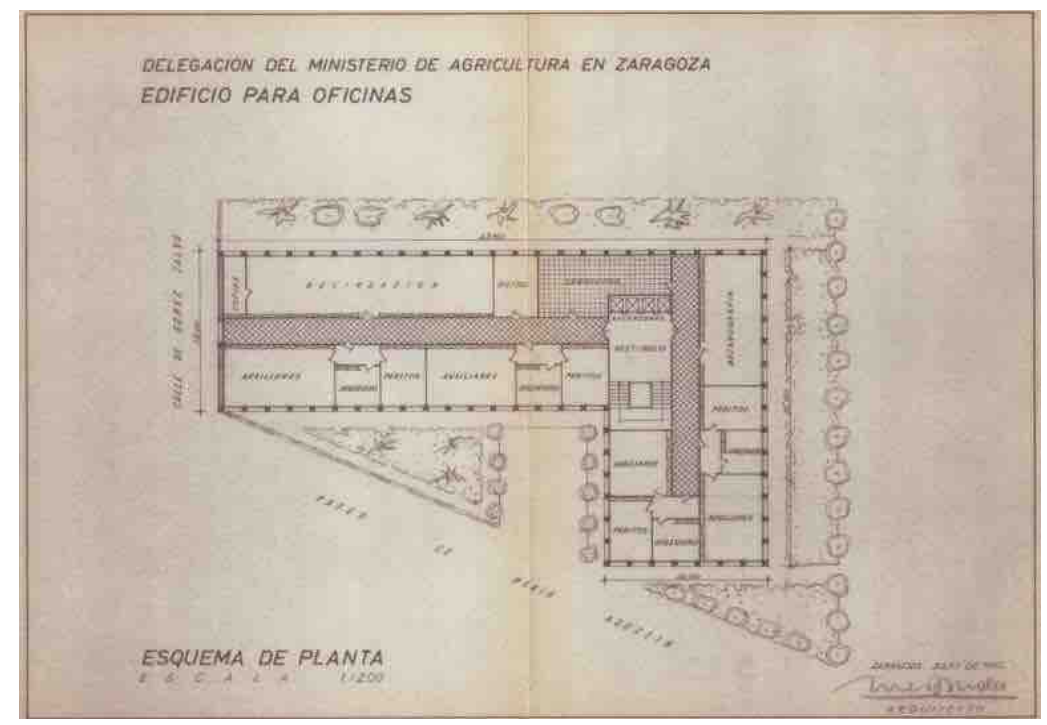

Fig. 17. Esquema de planta del edificio para las oficinas del Ministerio de Agricultura en Zaragoza, 1964 (Fuente: AHPZ, Zaragoza).

42 AHPZ, Sección INC, Caja A/25577, Exp. 5.092: «Avance de estudio de construcción de un edificio para los servicios del Ministerio de Agricultura en Zaragoza», Zaragoza, julio de 1964, p. 1.

43 Sobre esta cuestión, véase YESTE NAVARRO, I., La reforma interior ..., op . cit., pp. 274-287. 
Durante una visita del ministro de Agricultura a la zona del Canal de Aragón y Cataluña en abril de 1964 se volvió a estudiar el tema, concluyendo que no debía construirse únicamente una sede para el INC, sino para todos los Servicios dependientes del Ministerio de Agricultura situados en Zaragoza. Para analizar esta cuestión se nombró una comisión, que fue la encargada de gestionar las necesidades de los distintos Servicios a instalar en el nuevo edificio del Ministerio. Este equipo, compuesto entre otros profesionales por el ingeniero jefe de la Delegación del Ebro, Francisco de los Ríos, solicitó a José Borobio la colaboración y asesoramiento técnico en la redacción del proyecto. De este modo, con la anexión del solar número 1 de la citada parcelación se podría llevar a cabo la pretendida construcción.

El edificio albergaría los siguientes servicios: Jefatura Agronómica, Patrimonio Forestal del Estado, Distrito Forestal, Instituto Nacional de Colonización, Servicio Provincial de Ganadería, Servicio Nacional del Trigo, Instituto Nacional para la producción de semillas selectas, Estación de cultivos, Servicio Nacional de Algodón, Servicio de Conservación de suelos, Concentración Parcelaria y Extensión Agraria ${ }^{44}$. Tendría en planta una superficie de $700 \mathrm{~m}^{2}$-unos $500 \mathrm{~m}^{2}$ para despachos y oficinas por cada una-; y se compondría de 14 pisos destinados totalmente a oficinas (figuras 15-17). Las plantas baja y primera se dedicarían a los servicios comunes de información, recepción, salones de conferencias y exposiciones; y en los sótanos se dispondrían los almacenes y el garaje. El aspecto exterior del edificio, como recoge la memoria del proyecto, sería sobrio, con grandes ventanales para facilitar una buena iluminación y con una amplia zona verde en su entorno.

44 AHPZ, Sección INC, Caja A/25577, Exp. 5.092: «Avance de estudio de construcción de un edificio para los servicios del Ministerio de Agricultura en Zaragoza», Zaragoza, julio de 1964, p. 2. 

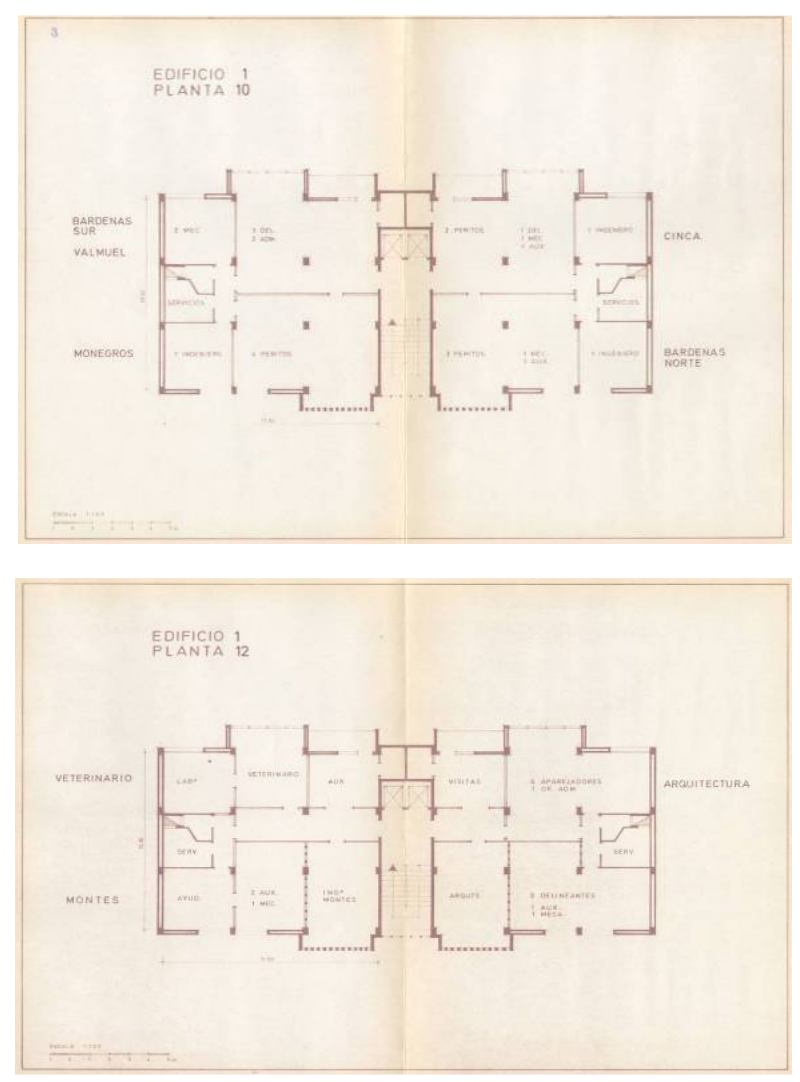

Figs. 18 y 19. Plantas 10 y 12 de las oficinas de la Delegación en la calle Vázquez de Mella, 1970 (Fuente: AHPZ, Zaragoza).

Aun así, este proyecto tampoco llegó a prosperar. Por este motivo, el 3 de febrero de 1970 tuvo lugar una reunión de la Comisión Coordinadora del Ministerio de Agricultura en la Estación Experimental de Aula Dei (CSIC), en Zaragoza. El motivo de este encuentro -al que asistió en representación del INC el ingeniero agrónomo Miguel Blasco Escudero- fue dar una solución al tema de la instalación conjunta de todos los organismos y servicios dependientes del Ministerio de Agricultura en un mismo edificio, dado que hasta este momento estaban dispersos por diferentes puntos de la ciudad. Es preciso recordar a este respecto que la reestructuración del citado Ministerio, el 1 de febrero de 1968, 
estableció que en cada una de las provincias españolas se reuniesen todos sus servicios en una Delegación Provincial ${ }^{45}$.

De este modo, en este encuentro se puso de manifiesto la gestión realizada con la inmobiliaria de la Caja de Ahorros y Monte de Piedad de Zaragoza, Aragón y Rioja -hoy Ibercaja-, para que arrendara al Ministerio de Agricultura parte del edificio que en ese momento estaba en construcción en la calle Vázquez de Mella -junto al paseo de Isabel la Católica y la vía de la Hispanidad-. Asimismo, se solicitó el asesoramiento del Servicio de Arquitectura del INC en lo referente a su distribución interior.

Aunque lo cierto es que no todos los servicios fueron partidarios de realizar este traslado provisional, dado que todavía se tenía presente la construcción del nuevo edificio:

"Por parte de algún Servicio se alegó los inconvenientes de la lejanía y lo innecesario que era hacer un traslado provisional para, dentro de cuatro o cinco años, hacer otro posterior. El Sr. Delegado explicó la metafísica del traslado diciendo que si éste traslado no se realizaba antes del mes de junio, perderían los cinco millones de pesetas que él conseguía del Banco de Aragón al dejar el Instituto sus oficinas en Teniente Coronel Valenzuela núm. 5, y que esta cantidad la necesitaba para la adquisición del futuro solar definitivo para la instalación de la Delegación"

Además, se señalaba que la lejanía al centro de la ciudad obligaría a aumentar la plantilla en lo referente a ordenanzas y recaderos. Este inmueble, compuesto de 18 plantas, presentaba también un inconveniente, según expresaron los afectados, a nivel de movilidad interna en el edificio, ya que únicamente contaba con dos ascensores, con uso compartido por parte de los usuarios y del personal de la plantilla.

La Delegación del Ebro, por su parte, había solicitado varias plantas del edificio para instalar en ellas sus servicios. Definitivamente, en el mes de diciembre de 1971 empezaron los traslados del personal a estas instalaciones, en los núms. 8 y 10 de la calle Vázquez de Mella ${ }^{47}$ (figuras 18-19). Comenzó la

45 «Decreto 161/1968, de 1 de febrero, sobre reorganización del Ministerio de Agricultura», Boletín Oficial del Estado, núm. 30, sábado 3 de febrero de 1968, pp. 1.623-1.627.

46 AHPZ, Sección INC, Caja A/25576, Exp. 5.071: «Informes sobre la propuesta formulada por el Delegado del Ministerio de Agricultura, para la instalación provisional de las oficinas de la Delegación del Ebro en el edificio conjunto del Ministerio de Agricultura», Zaragoza, abril de 1970, p. 2.

47 «Todos los Servicios de Agricultura, reunidos en un solo edificio», Amanecer, Zaragoza, viernes 3 de diciembre de 1971, p. 8; «Traslado de los servicios del Ministerio de Agricultura en Zaragoza», Hoja del Lunes, Zaragoza, lunes 6 de diciembre de 1971, p. 14. 
Sección Agronómica - el día 9-; seguidamente la Sección Forestal -a partir del día 13-; y la Sección Ganadera -desde el día 15-.

Así, el 25 de octubre de 1972 se firmó el contrato de arrendamiento, ocupando la planta 0 del área derecha del inmueble, $y$, de la parte izquierda, la mitad de la planta $4^{\mathrm{a}}$ y las plantas $5^{\mathrm{a}}$ a $12^{\mathrm{a}}$, además de 10 garajes. Además, se contó con otro local en el bajo del núm. 4 de la misma calle, donde se instaló el laboratorio geotécnico (antes en la calle Augusto Borderas núm. 5), que resultaba insuficiente.

Este fue el último emplazamiento de los servicios del Instituto, que desde julio de 1971 se había transformado en IRYDA. Además, se estableció una nueva organización en la Delegación Regional del Ebro, que pasó de ser un organismo de ámbito regional a disponer los servicios de forma dispersa en las diferentes provincias en las que actuó. Todo ello regido por la Inspección Regional del Ebro, con sede en Zaragoza ${ }^{48}$. Igualmente, se contó con otros inmuebles auxiliares, como un almacén en la calle Juan José Rivas, núm. 9 (donde se ubicó el Archivo Técnico), y un laboratorio en los núms. 5 y 7 de la calle de Riglos. Esta institución tenía también en propiedad los edificios del Centro Técnico de "La Alfranca", en Pastriz, y el vivero forestal "Santa Anastasia", en Ejea de los Caballeros ${ }^{49}$.

48 En la actualidad, los servicios del Ministerio de Agricultura en Zaragoza están situados en la plaza de San Pedro Nolasco, núm. 7, y en el Edificio Pignatelli (paseo de María Agustín).

49 «Real Decreto 643/1985, de 2 de abril, sobre valoración definitiva y ampliación de funciones traspasadas de la Administración del Estado a la Comunidad Autónoma de Aragón en materia de Reforma y Desarrollo Agrario», Boletín Oficial del Estado, núm. 112, viernes 10 de mayo de 1985, pp. 13.294-13.309. 
A su vez, se establecieron diferentes jefaturas provinciales. En el caso que nos ocupa, se crearon las de Zaragoza ${ }^{50}$, Huesca ${ }^{51}$, Teruel ${ }^{52}$, Pamplona ${ }^{53}$, Lé-

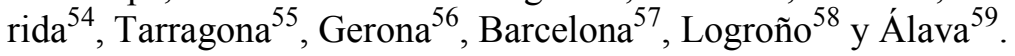

Éstas podían tener a su cargo, además, oficinas comarcales como, por ejemplo, la de Alcañiz (Teruel).

Por último, es preciso aludir a la organización interna de la Delegación del Ebro. En un primer momento, como señalamos anteriormente, funcionaron las

50 El director provincial del IRYDA en Zaragoza fue Fulgencio Sancho Bizcarra.

51 Las oficinas del IRYDA en Huesca se ubicaron en el edificio de Servicios Múltiples situado en la plaza de Cervantes, núm. 1. Además, contaba con un garaje en arriendo en la calle Flores de la misma ciudad, y unas oficinas y laboratorio en la localidad oscense de Sariñena. Igualmente, en el pueblo de El Temple, término municipal de Gurrea de Gállego, el IRYDA era el propietario del vivero forestal "La Escalereta". «Real Decreto 643/1985, de 2 de abril, sobre valoración definitiva y ampliación de funciones traspasadas de la Administración del Estado a la Comunidad Autónoma de Aragón en materia de Reforma y Desarrollo Agrario», Boletín Oficial del Estado, núm. 112, viernes 10 de mayo de 1985, pp. 13.294-13.309.

52 En Teruel, las oficinas estaban situadas en el edificio de Servicios Múltiples de la calle de San Francisco, núm. 27. Se contaba asimismo con un garaje arrendado y con una oficina comarcal y garaje en Alcañiz, en la calle Galán Bergua, núm. 27, donde se encontraba la Subjefatura provincial. «Real Decreto 643/1985, de 2 de abril, sobre valoración definitiva y ampliación de funciones traspasadas de la Administración del Estado a la Comunidad Autónoma de Aragón en materia de Reforma y Desarrollo Agrario», Boletín Oficial del Estado, núm. 112, viernes 10 de mayo de 1985, pp. 13.294-13.309.

53 Las oficinas del IRYDA en Navarra estaban emplazadas en la plaza de Conde Rodezno, núm. 8, en Pamplona. Este organismo contaba además con la propiedad de la residencia de trabajo de Figarol (Carcastillo). «Real Decreto 2654/1985, de 18 de diciembre, de traspaso de funciones y servicios de la Administración del Estado a la Comunidad Foral de Navarra en materia de agricultura, ganadería y montes», Boletín Oficial del Estado, núm. 25, miércoles 29 de enero de 1986, pp. 4.007-4.031.

54 Las oficinas del IRYDA en Lérida estaban ubicadas en calle Campo de Marte, núm. 35, en el edificio de Servicios Múltiples. Se contaba además con la propiedad de un vivero en Gimenells y del Centro Técnico y Residencia de Trabajo en la misma localidad. «Real Decreto 968/1986, de 25 de abril, por el que se amplían los traspasos de funciones y servicios de la Administración del Estado en materia de Reforma y Desarrollo Agrario a la Generalidad de Cataluña», Boletín Oficial del Estado, núm. 121, miércoles 21 de mayo de 1986, pp. 18.04218.048.

55 La sede del IRYDA en Tarragona se ubicó en la avenida de Cataluña, núm. 50, en el edificio Servicios Múltiples, y se contó con una oficina de trabajo en Tortosa, en la calle Alfonso XII, núm. 7. «Real Decreto 968/1986, de 25 de abril, por el que se amplían los traspasos de funciones y servicios de la Administración del Estado en materia de Reforma y Desarrollo Agrario a la Generalidad de Cataluña», Boletín Oficial del Estado, núm. 121, miércoles 21 de mayo de 1986, pp. 18.042-18.048.

56 Las oficinas del IRYDA en Gerona se situaron en la avenida de San Francisco, núm. 29, en el edificio de Servicios Múltiples. «Real Decreto 968/1986, de 25 de abril, por el que se amplían los traspasos de funciones y servicios de la Administración del Estado en materia de Reforma y Desarrollo Agrario a la Generalidad de Cataluña», Boletín Oficial del Estado, núm. 121, miércoles 21 de mayo de 1986, pp. 18.042-18.048.

57 Las oficinas de la Jefatura provincial de Barcelona se emplazaron en la calle Sabino Arana, núms. 22-24. «Real Decreto 241/1981, de 9 de enero, sobre traspaso de Servicios del Estado a la Generalidad de Cataluña en materia de Reforma y Desarrollo Agrario», Boletín Oficial del Estado, núm. 48, miércoles 25 de febrero de 1981, pp. 4.263-4.270.

58 Con sede en la calle Marqués de Murrieta, núm. 35, de Logroño, y siendo su jefe provincial José Cruz Pérez Lapazarán. «Real Decreto 1100/1985, de 5 de junio, sobre traspaso de funciones y servicios del Estado a la Comunidad Autónoma de La Rioja en materia de Reforma y Desarrollo Agrario», Boletín Oficial del Estado, núm. 161, sábado 6 de julio de 1985, pp. 21.310-21.315.

59 Estas oficinas se situaron en la calle Fueros, núm. 19, de Vitoria. 
oficinas de la Delegación Regional del Ebro y de la Delegación de Zaragoza refundida en la del Ebro en fecha 22 de junio de 1943-, que, junto con la de Tortosa, fueron las tres oficinas iniciales. En 1942 su plantilla estaba conformada de la siguiente manera ${ }^{60}$ :

\section{Delegación Regional del Ebro}

Jefe Deleg. $\quad$ Sin designar. Eventualmente, D. Pedro Mela Mela

Ing $^{\circ}$. Agro $^{\circ}$.

Sin designar

Perito Ag.

D. Jesús S. García Simón

Delineante

D. Luis Ferrer Olivera

Of. Adminis.

Sin designar

Aux. Adminis.

D. Felipe Antón Uña

Aux. Taquime.

Sin designar

Aux. Taquime.

Sin designar

Conductor

D. Julio Jiménez Aguilera

Ordenanza

Sin designar

Recadero

Sin designar

\section{Delegación de Zaragoza}

Jefe Deleg.

D. Pedro Mela Mela

Jefe Brig.

D. Francisco de los Ríos Romero

Perito Ag.

D. Francisco de P. Palou Medina

60 AHL, Sección INC, Caja 9. La información referente a la Delegación de Lérida será analizada en el apartado siguiente. 

Perito Ag.
D. José Estévez Pinal
Delineante
D. Roberto Rincón Porras
Of. Adminis
D. Juan Antonio Español Lacasta
Aux.Taquime
$\mathrm{St}^{\mathrm{a}}$ Rosario Fernández Trujillo

\section{Delegación de Tortosa}
Jefe Deleg.
D. José Miguel Galván Bello
Jefe Brig.
D. José Aragón Austri
Perito Ag.
D. Federico Ausina March
Perito Ag.
D. Luis Morante Rodríguez
Delineante
D. Miguel González Carod

Of. Adminis

Sin designar

Aux.Taquime

$\mathrm{St}^{\mathrm{a}}$ Ángela Muñoz Soler

Conductor

Sin designar

Ordenanza

Sin designar

Recadero

Sin designar

Poco a poco, se fueron definiendo los diferentes cargos, conformando la plantilla de la Delegación Regional del Ebro, que se caracterizó por la poca movilidad del personal que la componía. De este modo, Alejandro de Torrejón, ingeniero agrónomo, vino a Zaragoza como jefe de la Delegación del Ebro del INC, procedente del Protectorado de Marruecos ${ }^{61}$. $\mathrm{Su}$ nombramiento

61 Alejandro de Torrejón había tomado posesión del cargo de ingeniero jefe del Servicio Agronómico de la zona del Protectorado de España en Marruecos en marzo de 1942. «Orden de 7 de marzo de 1942 por la que se designa a don Alejandro Torrejón Montero para el cargo de Ingeniero Jefe del Servicio Agronómico de 
provisional se produjo el 18 de marzo de 1943, tomando posesión de su cargo el 6 de abril de ese año ${ }^{62}$. Así, su labor en tierras aragonesas pronto empezó a ser valorada en Madrid, como se deduce de la consulta de algunos expedientes firmados por él, lo que le valió posteriores ascensos ${ }^{63}$. Por Orden Ministerial de 3 de noviembre de 1944 fue nombrado jefe de la Sección Segunda del Instituto, puesto del que tomó posesión el 7 de noviembre del año citado. Mientras tanto siguió ocupando el cargo en la jefatura de la Delegación, por el que percibía una gratificación de 7.500 pesetas anuales "por mayor responsabilidad". Este salario lo mantuvo hasta julio de 1945. Seguidamente, el 7 de enero de 1946, fue cesado en el cargo de ingeniero jefe de la Delegación ${ }^{64}$, y, en noviembre de 1947, fue designado subdirector general de Obras y Proyectos del INC, puesto que mantuvo hasta agosto de $1951^{65}$, a consecuencia de su nombramiento, el 27 de julio de 1951, como director general del Instituto Nacional de Colonización ${ }^{66}$.

Le sucedió en el cargo de ingeniero jefe de la Delegación del Ebro el ingeniero agrónomo oscense Francisco de los Ríos Romero (1913-1995), hijo de Félix de los Ríos, uno de los autores de los planes de riegos del Alto Aragón y

la Zona de Protectorado de España en Marruecos», Boletín Oficial del Estado, núm. 72, viernes 13 de marzo de 1942, p. 1.807.

62 De manera simultánea, el ingeniero agrónomo Pedro Mela Mela cesó en el INC en mayo de 1943, pasando al Servicio Activo.

63 En julio de 1944, Alejandro de Torrejón redactó el Proyecto de Parcelación de los terrenos de vega adquiridos por el Instituto Nacional de Colonización en la localidad de Contamina, en la provincia de Zaragoza, trabajo que fue valorado muy favorablemente, como se constata por el informe suscrito por la Vicesecretaría Técnica en octubre del mismo año:

“[...] Se complace, sin embargo, el Ingeniero que suscribe en hacer presente a la Dirección la muy favorable impresión que la lectura del Proyecto le ha producido, por la justeza, meticulosidad y detalle con que están estudiadas todas las partes.

Tanto la elección de los distintos factores que el autor ha tenido en cuenta para llegar a una perfecta parcelación ajustada a la realidad topográfica y agronómica de las tierras y a las posibilidades económicas y de trabajo de los colonos, como la forma de ser conjugados aquellos factores en la parcelación propuesta, constituye un modelo de esta clase de trabajos".

AHPZ, Sección INC, Caja A/25167, Exp. 19: «Proyecto de parcelación de los terrenos de vega adquiridos por el I.N. de C. en Contamina (Zaragoza). Memoria», Zaragoza, julio de 1944.

64 AHPZ, Sección INC, Caja A/39958, Exp. Alejandro de Torrejón Montero.

65 «Decreto de 21 de noviembre de 1947 por el que se nombra subdirector de Obras y Proyectos del Instituto Nacional de Colonización al Ingeniero Agrónomo don Alejandro de Torrejón y Montero», Boletín Oficial del Estado, núm. 333, sábado, 29 de noviembre de 1947, p. 6.338; «Decreto de 17 de agosto de 1951 por el que cesa en el cargo de subdirector de Obras y Proyectos del Instituto Nacional de Colonización don Alejandro Torrejón y Montero», Boletín Oficial del Estado, núm. 238, domingo 26 de agosto de 1951, p. 4.004.

66 «Decreto de 27 de julio de 1951 por el que se nombra director general del Instituto Nacional de Colonización a don Alejandro Torrejón y Montero», Boletín Oficial del Estado, núm. 211, lunes 30 de julio de 1951, p. 3.577.

Asimismo, en mayo de 1948 se le había concedido el ingreso en la Orden Civil del Mérito Agrícola, con la categoría de Comendador de número. «Orden de 22 de mayo de 1948 por la que se concede el ingreso en la Orden Civil del Mérito Agrícola, con la categoría de Comendador de número, a don Alejandro Torrejón y Montero», Boletín Oficial del Estado, núm. 162, jueves 10 de junio de 1948, p. 2.409. 
de las Bardenas, que en este momento se encontraba exiliado en Venezuela ${ }^{67}$. Se tituló en Madrid en el año 1941, fecha en que quedó vacante un puesto en el Instituto Nacional de Colonización, en la sede de Zaragoza ${ }^{68}$. El 29 de noviembre de 1941 tomó posesión de su plaza como Ingeniero Auxiliar de la Brigada de Información del Ebro del $\mathrm{INC}^{69}$. Su espíritu de trabajo y entrega le llevó el 22 de junio de 1943 a ser el subjefe de la Delegación ${ }^{70}$. El 7 de enero de 1946, Francisco de los Ríos se hizo cargo de la jefatura de la Delegación Regional del Ebro del INC de manos de Faustino García Lozano, ingeniero agrónomo, y tras el traslado a Madrid de Alejandro de Torrejón, jefe accidental ${ }^{71}$ (figura 24).

Una vez transformado este organismo en IRYDA, el 12 de febrero de 1972 , fue nombrado Inspector Regional del Ebro; un cargo que mantuvo hasta el 10 de junio de 1972, fecha en que fue elegido jefe de la División Regional Agraria del Ebro del Instituto Nacional de Investigaciones Agrarias (I.N.I.A.) ${ }^{72}$-donde permaneció hasta su jubilación-, dejando su labor en el INC-IRYDA. Cesó de

67 Este hecho le produjo algunos comentarios por parte de otros cargos, como señala Alfonso Zapater: "Y eso que no le faltaron las reticencias hacia aquel "ingenierete", hijo de un exiliado, lo que le valió la velada amenaza de algún administrativo. ZAPATER, A., "Ha visto nacer 36 pueblos: Francisco de los Ríos, una vida dedicada a los riegos de Aragón”, publicado en 1988 en Heraldo de Aragón, Zaragoza, recogido en DE LOS RÍOS ROMERO, F., Cuarenta años..., op. cit., pp. 214-217.

68 MARCUELlO, J. R., Francisco de los Ríos, Zaragoza, Diputación General de Aragón, Departamento de Presidencia y Relaciones Institucionales, 1992, p. 47.

69 Con motivo de su jubilación como jefe del IRYDA, dos de sus compañeros, Gregorio Matallana y José Borobio, le ofrecieron un homenaje a través de una narración de su vida, documento del que hemos obtenido parte de esta información. "Don Francisco de los Ríos y Romero: esta es tu vida hasta el cese en el IRYDA... narrada en Zaragoza el 20 de octubre de 1973" (inédito). Archivo particular.

70 Este puesto lo ocupó después, desde el 13 de septiembre de 1946, el ingeniero agrónomo José Aragón Austri, que pasaría posteriormente a la Sección Quinta de los Servicios Centrales de Madrid.

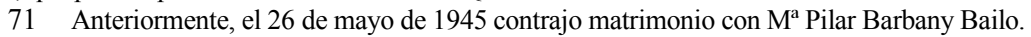

72 La División Regional del Ebro era denominada también División Regional Tercera (Ebro) o Tercera División Regional.

Por Decreto-Ley 17/1971, de 28 de octubre, se modificó la Administración institucional del Ministerio de Agricultura, creando el Instituto Nacional de Investigaciones Agrarias como organismo autónomo y fusionando en él las competencias que hasta ese momento competían al Instituto Nacional de Investigaciones Agronómicas, al Instituto Forestal de Investigaciones y Experiencias y al Patronato de Biología animal.

Por Decreto de 20 de abril de 1972 se aprobó su estructura orgánica, dictaminando su organización en unidades operacionales regionales que se encargaran de las actividades concernientes a la investigación agraria. Su presidente fue, desde el 5 de noviembre de 1971, José Lostao Camón, que había sido ingeniero agrónomo en la Delegación del Ebro del INC.

«Decreto 2684/1971, de 5 de noviembre, por el que se modifica la estructura orgánica del Ministerio de Agricultura», Boletín Oficial del Estado, núm. 266, sábado 6 de noviembre de 1971, p. 17.824-17.829; «Decreto 2706/1971, de 5 de noviembre, por el que se nombra Presidente del Instituto Nacional de Investigaciones Agrarias a don José Lostao Camón», Boletín Oficial del Estado, núm. 266, sábado 6 de noviembre de 1971, p. 17.833; «Decreto 1281/1972, de 20 de abril, por el que se aprueba la estructura orgánica del Instituto Nacional de Investigaciones Agraria (I.N.I.A.)», Boletín Oficial del Estado, núm. 122, lunes 22 de mayo de 1972, pp. 8.923-8.924; «Decreto 1469/1972, de 10 de junio, por el que se nombra jefe de la División Regional Agraria del Ebro a don Francisco de los Ríos Romero», Boletín Oficial del Estado, núm. 141, martes 13 de junio de 1972, p. 10.507. 
este cargo el 15 de septiembre de $1978^{73}$. Por tanto, este profesional se mantuvo al frente del INC en Zaragoza durante toda su trayectoria. Su labor fue reconocida en numerosas ocasiones, destacando en el año 1975 la concesión de la gran cruz de la Orden Civil del Mérito Agrícola ${ }^{74}$, y, el 23 de mayo de 1987, el nombramiento de Regante de Honor de Riegos del Alto Aragón ${ }^{75}$. Este recuerdo a su labor también se constata en un buen número de los pueblos de colonización, que dedicaron algunas de sus calles, plazas o edificios a su memoria $^{76}$.

\section{LA SEDE DE LA DELEGACIÓN DEL INSTITUTO NACIONAL DE CO- LONIZACIÓN EN LÉRIDA}

Como señalábamos anteriormente, en un principio se establecieron en diferentes zonas las denominadas Brigadas de Trabajo, que posteriormente, y tras la publicación de la circular núm. 54 (1942), se convirtieron en delegaciones provinciales. En el caso de la zona del Canal de Aragón y Cataluña su sede se estableció en la ciudad de Lérida.

Los trabajos comenzaron con la denominada "Brigada de Trabajo del Canal de Aragón y Cataluña”. Su jefe fue José Camino Aguirre, y se instaló en un principio en la calle San Anastasio, núm. 2, $1^{\circ}$. Posteriormente, el 3 de diciembre de 1941, y tras haber firmado el contrato de arrendamiento el 10 de septiembre de ese año, las oficinas de dicha Brigada se trasladaron a la calle de

73 Este cargo fue ocupado en ese momento por José Foncillas López. «Real Decreto 2201/1978, de 15 de septiembre, por el que cesa como jefe de la Tercera División Regional Agraria del Ebro don Francisco de los Ríos Romero», Boletín Oficial del Estado, núm. 223, lunes 18 de septiembre de 1978, pp. 21.780-21.781; «Real Decreto 2204/1978, de 15 de septiembre, por el que se nombra jefe de la Tercera División Regional Agraria del Ebro a don José Foncillas López», Boletín Oficial del Estado, núm. 223, lunes 18 de septiembre de 1978, p. 21.781 .

74 «Decreto 2285/1975, de 30 de septiembre, por el que se concede la Gran Cruz de la Orden Civil del Mérito Agrícola a don Pedro de Aristegui y Bengoa, don Guillermo Escardó Peinador, don Mariano Ganduxer Relats, don Enrique Pérez Hernández y Moreno, don Francisco de los Ríos Romero y don Heliodoro Rodríguez González», Boletín Oficial del Estado, núm. 235, miércoles 1 de octubre de 1975, p. 20.781.

75 Los actos se celebraron en el poblado de Tormos, junto al pantano de La Sotonera. Tras la entrega del reconocimiento a Francisco de los Ríos, éste aprovechó para homenajear a los agricultores y a los colonos con estas palabras: "que son unos grandes hombres [...] y yo os doy las gracias en representación de todos los viejos regantes que han luchado muchísimo". J. G. A., «La lluvia dio relevancia a la fiesta del regante en La Sotonera», Diario del Altoaragón, Huesca, domingo 24 de mayo de 1987, p. 9. Asimismo, fue declarado regante de honor en el "Día del Agua" celebrado en El Temple el 20 de mayo de 1989. BUETAS, R. J., «Más de dos mil personas participan en El Temple en el "Día del Agua"», Diario del Altoaragón, Huesca, domingo 21 de mayo de 1989 , p. 7.

76 En los pueblos de El Temple y Ontinar del Salz, por ejemplo, se le dedicó una calle; en San Jorge, la plaza Mayor; y en El Temple también recibe su nombre el colegio de este núcleo. 
Pescadería, núm. 1, entresuelo ${ }^{77}$-denominada entre 1945 y 1980 Capitán Salvador Masip, y en la actualidad Baixada de la Trinitat $-{ }^{78}$.

Seguidamente, por orden de la Dirección General de Colonización de 15 de junio de 1942, se suprimieron las Brigadas de Trabajo e Información, constituyéndose en este momento la Delegación de Lérida ${ }^{79}$, que quedó conformada internamente del modo siguiente:

\begin{tabular}{|c|c|}
\hline Ing $^{\circ}$. Agr ${ }^{\circ}$. Jefe de la Delegación & D. José Camino Aguirre \\
\hline Ing $^{\circ}$. Agr ${ }^{\circ}$. Jefe Brigada Agregado & D. Manuel García de Oteyza ${ }^{80}$ \\
\hline Ing $^{\circ}$. Agr ${ }^{\circ}$. Jefe Brigada Agregado & D. Mariano Laguna Reñina \\
\hline Ing $^{\circ}$. Agr ${ }^{\circ}$. Jefe Brigada Agregado & D. Antonio Pons Canals \\
\hline Perito Agrícola & D. José Gómez Sánchez \\
\hline Perito Agrícola & D. Jorge Pie Sopena \\
\hline Perito Agrícola & D. Ricardo Zubeldía Echevarría \\
\hline Perito Agrícola & Sin designar \\
\hline Perito Agrícola & Sin designar \\
\hline Delineante & D. Alberto Vereda Ugarte \\
\hline Delineante & D. Fernando Quintero Carballo \\
\hline Oficial Administrativo & D. Marcelino Puig Palasí \\
\hline
\end{tabular}

77 También se dispuso de otros locales, como un bajo en la calle de San Martín, núm. 62, habilitado como almacén para la maquinaria agrícola y tractores pertenecientes a la Delegación. AHL, Sección INC, Caja 8.

78 Información facilitada por el personal del Arxiu Municipal de Lleida.

79 " $2^{\circ}$.- Las diversas Brigadas de Trabajo y Explotación que tienen su residencia en esa localidad, se reúnen para constituir una Delegación que se llamará Delegación de Lérida. Como jefe de Dicha Delegación figura el Ingeniero Agrónomo de mayor antigüedad, y aunque en el aspecto técnico cada Brigada tendrá la independencia que requiera su trabajo, en el administrativo dependerán y estarán a las órdenes de dicho jefe que en definitiva distribuirá el personal de acuerdo con las necesidades del servicio y órdenes recibidas de la Dirección General". AHL, Sección INC, Caja 9.

80 En abril de 1943, la Dirección General nombró a Manuel García Oteyza subjefe de la Delegación Regional del Guadiana, con residencia en Badajoz. AHL, Sección INC, Caja 11, Exp. Personal. 
Oficial Administrativo

Auxiliar Administrativo

Auxiliar Administrativo

Auxiliar Taquimecanógrafo

Auxiliar Taquimecanógrafo

Conductor

Conductor

Ordenanza

Ordenanza
Sin designar

D. Julio Sancho del Palacio

Sin designar

D a Casilda Torres Fernández Arróyabe

Sin designar

D. José Luis Gil Miguel

D. Avelino Zapiaín Sanz

Sin designar

Sin designar

Seguidamente, por orden de la Dirección General de Colonización de 15 de junio de 1942, se suprimieron las Brigadas de Trabajo e Información, constituyéndose en este momento la Delegación de Lérida ${ }^{81}$, que quedó conformada internamente del modo siguiente:
Ing $^{\mathrm{o}}$. Agr ${ }^{\circ}$. Jefe de la Delegación
D. José Camino Aguirre
Ing $^{\mathrm{o}}$. Agr ${ }^{\circ}$. Jefe Brigada Agregado
D. Manuel García de Oteyza ${ }^{82}$
Ing $^{\circ}$. Agr ${ }^{\circ}$. Jefe Brigada Agregado
D. Mariano Laguna Reñina
Ing $^{\mathrm{o}}$. Agr ${ }^{\mathrm{o}}$. Jefe Brigada Agregado
D. Antonio Pons Canals

81 " $2{ }^{\circ}$.- Las diversas Brigadas de Trabajo y Explotación que tienen su residencia en esa localidad, se reúnen para constituir una Delegación que se llamará Delegación de Lérida. Como jefe de Dicha Delegación figura el Ingeniero Agrónomo de mayor antigüedad, y aunque en el aspecto técnico cada Brigada tendrá la independencia que requiera su trabajo, en el administrativo dependerán y estarán a las órdenes de dicho jefe que en definitiva distribuirá el personal de acuerdo con las necesidades del servicio y órdenes recibidas de la Dirección General". AHL, Sección INC, Caja 9.

82 En abril de 1943, la Dirección General nombró a Manuel García Oteyza subjefe de la Delegación Regional del Guadiana, con residencia en Badajoz. AHL, Sección INC, Caja 11, Exp. Personal. 


\begin{tabular}{|c|c|}
\hline Perito Agrícola & D. José Gómez Sánchez \\
\hline Perito Agrícola & D. Jorge Pie Sopena \\
\hline Perito Agrícola & D. Ricardo Zubeldía Echevarría \\
\hline Perito Agrícola & Sin designar \\
\hline Perito Agrícola & Sin designar \\
\hline Delineante & D. Alberto Vereda Ugarte \\
\hline Delineante & D. Fernando Quintero Carballo \\
\hline Oficial Administrativo & D. Marcelino Puig Palasí \\
\hline Oficial Administrativo & Sin designar \\
\hline Auxiliar Administrativo & D. Julio Sancho del Palacio \\
\hline Auxiliar Administrativo & Sin designar \\
\hline Auxiliar Taquimecanógrafo & Da Casilda Torres Fernández Arróyabe \\
\hline Auxiliar Taquimecanógrafo & Sin designar \\
\hline Conductor & D. José Luis Gil Miguel \\
\hline Conductor & D. Avelino Zapiaín Sanz \\
\hline Ordenanza & Sin designar \\
\hline Ordenanza & Sin designar \\
\hline
\end{tabular}

El 10 de julio de 1943 cesó en su cargo José Camino Aguirre, tomando la dirección, por orden del director general de Colonización, como ingeniero jefe de la Delegación de Lérida, Mariano Laguna Reñina ${ }^{83}$. Se mantuvo en este puesto hasta el 31 de marzo de 1952, fecha en que fue trasladado a los Servicios

83 AHL, Sección INC, Caja 1. Por este cargo, recibía una "gratificación anual de cinco mil pesetas por mayor responsabilidad". 
Centrales del INC en Madrid -Sección Tercera- ${ }^{84}$, ocupando la jefatura el ingeniero agrónomo José Baquero de la Cruz. Éste tuvo que asumir, en algunas ocasiones, y con motivo de las tareas profesionales del ingeniero Laguna, la dirección de forma accidental ${ }^{85}$. El ingeniero subjefe fue Justo González Niño.

Así, el 10 de septiembre de 1945, la sede de esta Delegación se trasladó del domicilio de la calle Capitán Salvador Masip al local de la calle del Carmen, núms. 1 y 3 , primer piso ${ }^{86}$. Asimismo, se dispuso de un pequeño almacén en la calle Litera, núm. 2, donde se depositó el denominado "archivo muerto". Este nuevo local estaba concebido para cumplir funciones de vivienda, por lo que la instalación, como recogió el jefe de la Delegación en un escrito fechado en 1964, no era demasiado adecuada:

"[...] como las actuales oficinas se han montado en un inmueble que estaba destinado a vivienda, ocupándose dos de estas para las distintas dependencias, no pueden estar bien ordenadas ni relacionadas a los efectos del rendimiento de trabajo, pero lo peor es que la mayor parte de las habitaciones no disponen de luz directa, lo que si en todo momento es inconveniente, aún lo es más para el trabajo que desarrolla el Instituto en relación con la confección de planos, delineación, etc. ${ }^{, 87}$.

Por este motivo, en julio de 1964, el Gobernador Civil de la provincia de Lérida envió una carta al jefe de la Delegación, en la que se requirió un informe sobre los inmuebles ocupados por el Instituto en esta ciudad, dado que se estaba estudiando la concentración de todos los servicios estatales en un solo edificio -de manera análoga a lo sucedido en Zaragoza-. Pero esta propuesta no prosperó en ese momento, como se refleja en el escrito elevado por la Delegación a la Dirección General de Colonización en noviembre de 1965 en el que solicitaba autorización para alquilar un nuevo local de oficinas: "ya que el que actualmente se lleva en arriendo no reúne condiciones por estar situado dentro del casco urbano antiguo y rodeado de calles estrechas", a lo que la Dirección General aceptó. Pero la propuesta no se llevó a efecto.

84 Por Decreto 2915/1965 de 11 de octubre, fue nombrado Secretario General del Instituto Nacional de Colonización. «Decreto 2915/1965, de 11 de octubre, por el que se nombra Secretario general del Instituto Nacional de Colonización a don Mariano Laguna Reñina», Boletín Oficial del Estado, núm. 245, miércoles 13 de octubre de 1965 , p. 13.904.

85 También fue sustituido por los ingenieros agrónomos Gabriel Baquero de la Cruz -el ingeniero agrónomo más antiguo de la Delegación-, Justo González Niño, Mariano Valderrama Blat y Luis de Nicolás Andrés.

86 AHL, Sección INC, Caja 15. En este momento, el local que hasta ahora tenía en arriendo la Delegación de Lérida pasaría a ocuparlo la Jefatura Agronómica.

87 AHL, Sección INC, Caja 128. 
Hay que indicar además que esta Delegación se ocupó de los proyectos y trabajos del INC en las provincias de Barcelona, Gerona y Tarragona ${ }^{88}$. Pero en el año 1965, con ocasión de la intensificación de los trabajos en las zonas regables del Muga, Fluvía, Ter, Llobregat y Bajo Ebro -además de las que ya se estaban realizando en el Bajo Ampurdán-, así como la actuación en los pequeños regadíos, y debido a la necesidad de ejercer un más estrecho contacto con la Confederación del Pirineo Oriental, era aconsejable situar en Barcelona al personal del INC. En consecuencia, se planteó la creación de una subdelegación del Instituto en esta ciudad: "con residencia en dicha capital y con jurisdicción en el territorio de las provincias de Gerona, Barcelona y la parte de Tarragona adscrita hidráulicamente a la Confederación del Pirineo Oriental" ${ }^{\prime 29}$. Aunque, y hasta que no se fundó oficialmente como Delegación, los servicios dependieron administrativa y económicamente de la de Lérida. Asimismo, desde 1969 se le encomendaron trabajos de la zona del delta del Ebro ${ }^{90}$.

Finalmente, en los años setenta, y después de la transformación del INC en el IRYDA, la sede de la entonces denominada jefatura provincial de Lérida se trasladó al edificio de Servicios Múltiples ubicado en la calle Campo de Marte, núm. 35. Además, se contó con la propiedad de un vivero en Gimenells y del Centro Técnico y Residencia de Trabajo en la misma localidad ${ }^{91}$. Es preciso mencionar por último que las zonas de Gerona y Barcelona, que durante un tiempo se gestionaron desde la Delegación Provincial de Lérida, contaron también en este momento con su jefatura provincial, igual que Tarragona ${ }^{92}$.

88 La Delegación de Lérida gestionaba la parte de la provincia de Tarragona correspondiente a la Confederación Hidrográfica del Pirineo Oriental, dado que la parte relativa a la Confederación Hidrográfica del Ebro -donde se ubicó el núcleo de Villafranco del Delta (actual Poble Nou del Delta)- estaba adscrita a la Delegación Regional del Ebro, con sede en Zaragoza.

89 Su plantilla estaba compuesta por el siguiente personal: un ingeniero agrónomo -que ostentaría el cargo de jefe de la Delegación, y al mismo tiempo subjefe de la Delegación de Lérida (Francisco Vall-Llosera Vilaplana)-; un perito agrícola; un oficial administrativo; un delineante; un auxiliar administrativo; un auxiliar taquimecanógrafo; un ordenanza y un recadero. AHL, Sección INC, Caja 135.

90 En 1969, al ser encomendado al INC el saneamiento de la zona del delta del Ebro, la Dirección General dispuso que la Delegación de Lérida se hiciese cargo de todos los trabajos en esa zona de Lérida, que hasta ese momento habían sido atendidos por la Delegación del Ebro. AHL, Sección INC, Caja 829, Exp. 777, «Plan de explotación de la finca del delta derecho del Ebro (Tarragona) del Instituto Nacional de Colonización», Lérida, noviembre de 1969 , p. 1.

91 «Real Decreto 968/1986, de 25 de abril, por el que se amplían los traspasos de funciones y servicios de la Administración del Estado en materia de reforma y desarrollo agrario a la Generalidad de Cataluña», Boletín Oficial del Estado, núm. 121, miércoles 21 de mayo de 1986, pp. 18.042-18.048.

92 Las oficinas del IRYDA en Gerona se situaron en la avenida de San Francisco, núm. 29, en el edificio de servicios múltiples. «Real Decreto 968/1986, de 25 de abril, por el que se amplían los traspasos de funciones y servicios de la Administración del Estado en materia de reforma y desarrollo agrario a la Generalidad de Cataluña», Boletín Oficial del Estado, núm. 121, miércoles 21 de mayo de 1986, pp. 18.042-18.048; las oficinas del IRYDA en Tarragona se ubicaron en la avenida de Cataluña, núm. 50, en el edificio servicios múltiples, y con una oficina de trabajo en Tortosa, en la calle Alfonso XII, núm. 7. «Real Decreto 968/1986, de 25 de abril, 
En definitiva, se constata cómo se crearon diferentes sedes en las que se instalaron las oficinas del INC en la cuenca del Ebro, siguiendo las directrices de la Dirección General, que determinó dónde tenían que ubicarse -siempre en emplazamientos importantes y céntricos a nivel urbano-. Igualmente, queda reflejado que no dispusieron de un espacio construido ex-profeso para este fin, pese a ser la Delegación del Ebro una de las más importantes del Instituto.

\author{
José María Alagón Laste \\ Departamento de Historia del Arte \\ Área de Historia del Arte \\ Facultad de Filosofía y Letras \\ Universidad de Zaragoza \\ Pabellón Central de Filosofía y Letras \\ C/ San Juan Bosco, 7 \\ 50009 Zaragoza, (España) \\ https://orcid.org/0000-0001-8288-3262 \\ jmalagon@unizar.es
}

por el que se amplían los traspasos de funciones y servicios de la Administración del Estado en materia de reforma y desarrollo agrario a la Generalidad de Cataluña», Boletín Oficial del Estado, núm. 121, miércoles 21 de mayo de 1986, pp. 18.042-18.048; Las oficinas de la Jefatura provincial de Barcelona se emplazaron en la calle Sabino Arana números 22-24. «Real Decreto 241/1981, de 9 de enero, sobre traspaso de Servicios del Estado a la Generalidad de Cataluña en materia de reforma y desarrollo agrario», Boletín Oficial del Estado, núm. 48, miércoles 25 de febrero de 1981, pp. 4.263-4.270. 